\title{
Life expectancy and economic growth: the role of the demographic transition
}

\author{
Matteo Cervellati · Uwe Sunde
}

Published online: 11 May 2011

(C) Springer Science+Business Media, LLC 2011

\begin{abstract}
This paper investigates the hypothesis that the causal effect of life expectancy on income per capita growth is non-monotonic. This hypothesis follows from the recent literature on unified growth, in which the demographic transition represents an important turning point for population dynamics and hence plays a central role for the transition from stagnation to growth. Results from different empirical specifications and identification strategies document that the effect is non-monotonic, negative (but often insignificant) before the onset of the demographic transition, but strongly positive after its onset. The results provide a new interpretation of the contradictory existing evidence and have relevant policy implications.
\end{abstract}

Keywords Life expectancy · Income growth - Demographic transition - Population growth $\cdot$ Fertility $\cdot$ Unified growth theories $\cdot$ Non-Linear dynamics $\cdot$ Non-monotocities · IV estimates $\cdot$ Epidemiological revolution

JEL Classification $\mathrm{J} 10 \cdot \mathrm{J} 13 \cdot \mathrm{N} 30 \cdot \mathrm{O} 10 \cdot \mathrm{O} 40 \cdot \mathrm{E} 10$

Electronic supplementary material The online version of this article (doi:10.1007/s10887-011-9065-2) contains supplementary material, which is available to authorized users.

\author{
M. Cervellati \\ University of Bologna, Bologna, Italy \\ e-mail: m.cervellati@unibo.it \\ U. Sunde $(\varangle)$ \\ University of St. Gallen, St. Gallen, Switzerland \\ e-mail: uwe.sunde@unisg.ch \\ M. Cervellati · U. Sunde \\ IZA, Bonn, Germany \\ U. Sunde \\ CEPR, London, UK
}




\section{Introduction}

Across countries, high life expectancy is associated with high income per capita. The question whether improvements in life expectancy cause increases in per capita income is the subject of a lively debate, however. Lorentzen et al. (2008), exploit exogenous variation in mortality across countries and find that life expectancy causally leads to faster economic growth. ${ }^{1}$ Exploiting exogenous changes in mortality in the context of the epidemiological transition, Acemoglu and Johnson (2007) come to opposite results: improvements in life expectancy mainly trigger faster population growth, but have a negative causal effect on income per capita. These findings have very important implications for academic research as well as for the policy debate since they challenge the view that reducing mortality and improving health is beneficial also for economic development. ${ }^{2}$

This paper addresses the question of the causal effect of life expectancy on economic growth from the perspective of the recent literature on unified growth in which the demographic transition has been shown to play a central role for the transition from stagnation to growth. This leads us to focus attention on the largely unexplored issue of the appropriate specification of the empirical analysis, rather than concentrating exclusively on the problem of the econometric identification in linear regression frameworks. From a theoretical perspective, the effect of life expectancy on income per capita is generally ambiguous. Lower mortality may increase the productivity of available resources thereby increasing total production. ${ }^{3}$ Lower mortality may, on the other hand, accelerate population growth and thereby reduce growth in income per capita in the presence of Malthusian effects.

The analysis of the appropriate empirical specification is motivated by the stylized facts about the dynamic evolution of mortality, fertility and population growth over the course of the, so called, "demographic transition". A key feature of the demographic transition is that, after an initial increase, the natural rate of population growth eventually falls in association with reductions in mortality and fertility. ${ }^{4}$ The implications of this demographic transition for economic development have been recently investigated by economists that study the transition from stagnation to growth within a unified framework following the seminal contribution by Galor and Weil (2000). An important implication of the non-monotonic population dynamics along the demographic transition is that the negative effects of population growth may be

\footnotetext{
${ }^{1}$ Findings of a positive effect of life expectancy on income per capita based on cross-country regressions are reported by Bloom and Sachs (1998), Gallup et al. (1999), and Bloom et al. (2003), among others. The works by Shastry and Weil (2003), Weil (2007) and Ashraf et al. (2008) exploit a different strategy and use calibrations based on microeconomic estimates to infer the role of health improvements for income per capita. The results suggest positive, but comparably small, effects on income per capita.

2 Beyond the effect of life expectancy on income, reductions in mortality may increase individual well being directly by extending the lifetime horizon or the quality of life, as investigated, e.g., by Becker et al. (2005) or Murphy and Topel (2006). In this paper we exclusively concentrate attention on the effect of life expectancy on individual well-being through changes in income per capita.

3 Theories studying the positive effects of life expectancy on income production (abstracting from changes in fertility) include de la Croix and Licandro (1999), Kalemli-Ozcan et al. (2000), Blackburn and Cipriani (2002), Boucekkine et al. (2002), Boucekkine et al. (2003), Lagerlöf (2003), Cervellati and Sunde (2005), Bar and Leukhina (2011), among others. The works by Bleakley (2007), Bleakley and Lange (2009) and Jayachandran and Lleras-Muney (2009) provide robust evidence that better health and higher life expectancy increase educational attainments at the individual level.

4 These non-monotonic patterns of population growth and fertility have been widely documented across different countries and times as discussed in Sect. 2, and they are also apparent in the sample of countries studied in this paper.
} 
at work before, but not after, the onset of the demographic transition. ${ }^{5}$ The literature has also pointed out that life expectancy may accelerate income growth after the onset of the demographic transition by affecting the age structure of the population and the dependency ratio, by improving educational attainment and by increasing female labor force participation in association with reduced fertility. ${ }^{6}$ Finally, it has been documented that the reliance on fix factors of production, which may be responsible for congestion effects, is typically larger for countries at low levels of economic and demographic development (see Weil and Wilde 2009). Taken together, these arguments suggest that the demographic transition is a crucial turning point for many direct and indirect channels through which life expectancy affects income per capita. As consequence, the effect of life expectancy on income per capita may be ambiguous before the demographic transition, but should be unambiguously positive after its onset.

We investigate this hypothesis using the same cross-country panel data for the period 1940-2000 as in the influential paper by Acemoglu and Johnson (2007). As preliminary analysis, we study the dynamic patterns of life expectancy and fertility to identify the onset of the demographic transition in each country in the sample, based on the classification criteria used in the demography literature. In line with the previous literature, we find that the dynamic patterns are consistent with the stylized dynamics of the demographic transition. About half of the countries in the sample had already experienced the onset of the demographic transition by 1940. In these countries, which we call "post-transitional" in the remainder of this paper, increases in life expectancy after 1940 went along with reductions in both fertility and population growth. In the other countries, which we call "pre-transitional", improvements in life expectancy were associated with increases in population growth after $1940 .{ }^{7}$

To estimate the causal effect of life expectancy on income growth, we use the specification and identification strategy based on the predicted mortality instrument proposed by Acemoglu and Johnson (2007) as benchmark. This identification strategy exploits exogenous variation in life expectancy due to the epidemiological transition after 1940. The analysis is also performed using the alternative instrumentation proposed by Lorentzen et al. (2008). We allow for heterogenous effects of life expectancy during the process of development by applying different empirical strategies. After showing that neglected non-linearities cannot be rejected in linear models estimated on the pooled sample, we adopt empirical specifications that allow for different effects of life expectancy depending on whether a country

\footnotetext{
5 Galor and Moav (2002) study the role of survival and natural selection for the fertility transition. Theories where greater life expectancy causally leads to a reduction in fertility include Kalemli-Ozcan (2002), which also explicitly shows that changes in fertility may lead to non-monotonicities in income per capita growth, Boldrin and Jones (2002), Kalemli-Ozcan (2003), Soares (2005), Strulik (2008) and Bar and Leukhina (2010); see Galor $(2005,2010)$ for comprehensive surveys of the literature. Whether reductions in mortality are indeed causal for fertility reductions is still debated in the empirical literature.

6 The role of dependency ratios is studied in Bloom et al. (2003), and the interaction between fertility and labor force participation is investigated by Bloom et al. (2009). Soares (2005), Cervellati and Sunde (2007), de la Croix and Licandro (2007) provide theories where life expectancy increases investments in human capital in association with a reduction in fertility. Falcão and Soares (2008) extend the analysis of female labor force participation and fertility by Galor and Weil (1996) to the consideration of the role of life expectancy.

7 Notice that, strictly speaking all countries are at different stages of their demographic transition in 1940. We call those countries "post-transitional" that had already experienced the onset of the transition by 1940 by the criteria from the demography literature discussed below, even if they might not have completed the transition (that is, even if they might still exhibited fertility above reproduction levels). Symmetrically, we call the other countries "pre-transitional". This is discussed in more details in Sect. 2.
} 
was pre-transitional or post-transitional already in 1940, that is, before the treatment of the epidemiological transition. The specification estimated by Acemoglu and Johnson (2007) is therefore nested in this approach, which relaxes the constraint that the effect of life expectancy on income growth is identical in pre-transitional and post-transitional countries.

The results document a strong and robust positive causal effect of life expectancy on income per capita in post-transitional countries, which is complemented by a significant negative effect on population growth. The opposite findings emerge for pre-transitional countries, although the negative effect on income is sometimes insignificant. The equality of the causal effects in pre-transitional and post-transitional countries can generally be rejected. The positive effect in post-transitional countries is larger than the average effect reported by Acemoglu and Johnson (2007), and opposite in sign. The analysis delivers qualitatively identical results when using the instruments proposed by Lorentzen et al. (2008). These findings document that the different results reported in the literature are not due to the different identifying variation, but due to the different sample composition in combination with linear empirical models that impose the effect of life expectancy to be identical across all countries in the sample. This is also documented using a linear estimation framework in the full sample but varying the weights of the different countries based on their demographic situation in 1940, without having to rely on a classification of the countries' demographic development in 1940. Simple decompositions further document that the differences in GDP growth can be mainly attributed to the difference in coefficients across pre-transitional and post-transitional countries, rather than to different variations in life expectancy or different time trends. The results are confirmed by a series of robustness checks including the consideration of alternative classifications of countries, the instrumentation of the demographic status of the different countries in 1940 using time invariant geographical characteristics and the inclusion of initial conditions in terms of GDP per capita and life expectancy, among others. The finding of a heterogenous effect of life expectancy on income per capita and population growth in pre- and post-transitional countries emerges consistently. Taken together, the results strongly support the view of long-run economic development as a non-linear process that is closely linked to non-monotonic population dynamics. These findings are complemented by additional evidence showing that increases in life expectancy causally increase the probability of observing the onset of the transition leading to lower fertility and birth rates.

The results contribute to the literature on the role of health for economic growth by accounting for the differential effects of life expectancy during the different phases of demographic development. Despite the existence of several theoretical arguments that can be used to motivate the hypothesis, these heterogeneous effects have not been documented systematically. The findings also help reconciling the seemingly contradictory empirical results in the literature by explicitly showing that they are not due to different instrumentation strategies but rather a consequence of a restrictive econometric specification together with a particular sample composition. In a broader perspective, the results are relevant for the empirical growth literature by highlighting the importance of accounting for non-linearities, or even non-monotonicities, in the development dynamics when conducting growth regressions over long periods of time. Finally, in view of the fact that most developing countries have recently experienced the onset of the demographic transition, the results have relevant policy implications.

The paper is structured as follows. Section 2 lays down the testable hypothesis and the estimation framework. Section 3 describes the data and the identification strategies. Section 4 presents the results and some robustness analysis. Section 5 concludes. Additional material is relegated to an Online Appendix. 


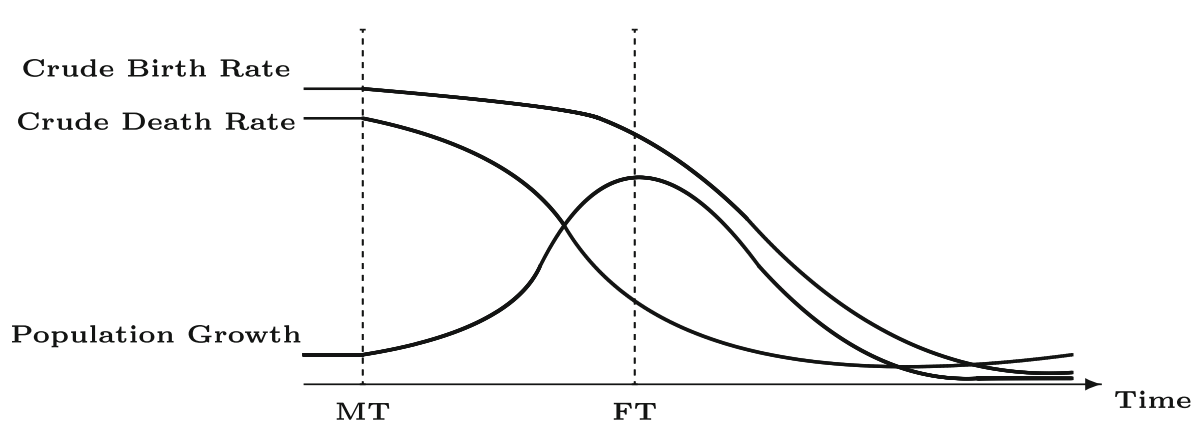

Fig. 1 The demographic transition

\section{Testable hypothesis and estimation framework}

\subsection{The demographic transition and its implications for the empirical specification}

A common feature of all episodes of the demographic transition is that the correlation between life expectancy and fertility eventually becomes negative. Already the early writers noticed that mortality reductions generally preceded the fertility reductions, although the delay of the fertility decline compared to the mortality reductions differed across European countries. A large body of research devoted to identifying the specific differences in the transition process and their timing across regions and countries has documented the stylized facts that also apply to subsequent transitions. ${ }^{8}$ As pointed out by Kirk (1996, p. 367) also "in non-European countries, the regularities are impressive. In every instance mortality has declined first and has been followed by declining fertility, and the result in each case has been a considerable acceleration in population growth".

The stylized textbook pattern of the demographic transition is presented in Fig. 1. ${ }^{9}$ Pretransitional countries are characterized by high mortality and fertility, reflected by high death and birth rates. The growth rate of population is generally positive but small. According to the typical representation, the demographic transition starts with a reduction in mortality rates, MT, while birth rates remain high. With some delay, fertility also drops, marking the onset of the fertility transition, FT, which represents the important turning point for population growth. The delay between MT and FT induces the typical hump-shaped pattern of population growth, which initially increases due to the lower mortality but eventually slows down since reduced fertility more than compensates the mechanical increase in population in response to lower mortality rates. ${ }^{10}$

\footnotetext{
8 Thompson (1929) was first in highlighting the unprecedented marked reduction in mortality and fertility rates within a fairly short period of time in the late 19th and early 20th Century in some Western countries. Subsequently, Landry (1934), Carr-Saunders (1936), and Notestein (1945) presented the first wave of systematic cross-country investigations of patterns of mortality, fertility and natural rates of population growth and initiated the study of the demographic transition as a leading topic of modern scientific demography. The European Fertility Project organized by Coale materialized in a massive study of fertility declines in 600 European administrative divisions in Europe between 1870 and 1960.

${ }^{9}$ Figure 1 reproduces Fig. 1.1 from Chesnais (1992) and Fig. 4.2 from Livi-Bacci (1992). These patterns are also used as base for population forecasts by e.g. the UN and the World Bank. For surveys on the demographic transition and its economic implications see also Lee (2003), and Galor (2005).

${ }^{10}$ Notice that the figure plots crude birth and death rates, that is, the total number of births and deaths divided by the size of the total population alive at each point in time. In the initial phase after MT, the birth rates decline slightly as consequence of the increase in population size although total fertility is unchanged. If death
} 


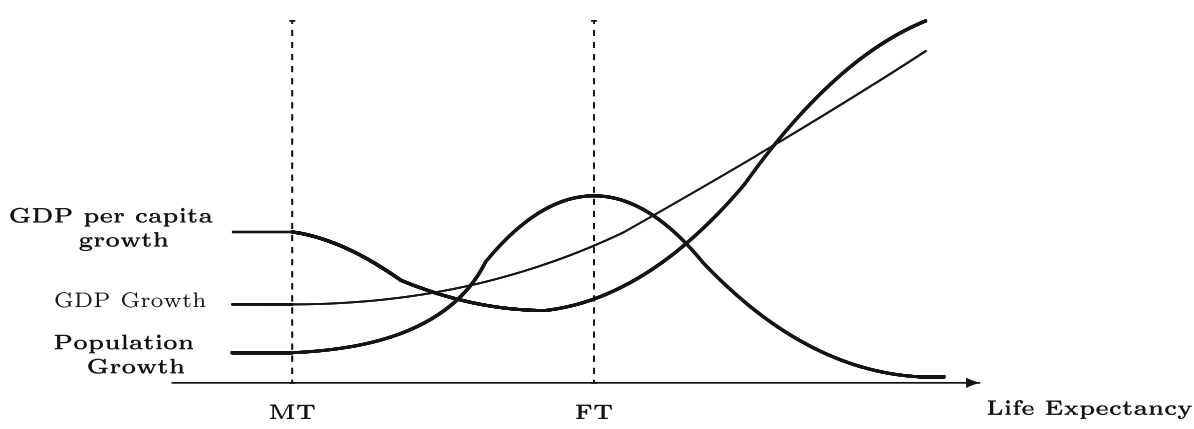

Fig. 2 Demographic dynamics and income growth

Increased life expectancy might have a negative effect on growth in income per capita if it accelerates population growth, for instance in the presence of Malthusian mechanisms. In fact, this is the main explanation by Acemoglu and Johnson (2007) for their finding of a negative causal effect of life expectancy. In all countries that undergo the demographic transition, however, increases in life expectancy are eventually negatively associated with population growth. This observation is crucial, because if an increase in life expectancy leads to lower fertility and population growth, then the negative effects of life expectancy on per capita income growth cannot be at work after the demographic transition, irrespective of the actual mechanism behind the demographic transition. Furthermore, as discussed above, the reliance on fixed resources appears more important at low levels of development and the non-Malthusian mechanisms that imply a positive relationship between life expectancy and growth are expected to gain momentum after the onset of the demographic transition. Taken together these observations jointly support the main testable hypothesis which is illustrated in Fig. 2: the effect of life expectancy on income per capita can be negative only before the onset of the demographic transition.

\subsection{Theoretical illustration}

The main hypothesis can be illustrated within the framework of Acemoglu and Johnson (2007). Consider a closed-economy in continuous time $t$, where a unique consumption good $Y$ is produced with a constant returns to scale aggregate production function

$$
Y_{t}=\left(A_{t} H_{t}\right)^{\alpha} L_{t}^{1-\alpha}
$$

where $0<\alpha<1$ and $L_{t}$ denotes factors of production like physical capital or land, which are assumed to be fixed and independent from life expectancy. ${ }^{11}$ The aggregate human capital is supplied inelastically and is given by $H_{t}=h_{t} N_{t}$, where $h_{t}$ denotes the (average) individual level of human capital and $N_{t}$ is population size; $A_{t}$ represents the level of technology (or productivity). Denote by $T_{t}$ the level of life expectancy. In Acemoglu and Johnson (2007), the role of life expectancy for total factor productivity and human capital is assumed to be iso-elastic, $A_{t}=\bar{A} T_{t}^{\theta}$, with $\theta \geq 0$, and $h_{t}=\bar{h} T_{t}^{\eta}$ with $\eta \geq 0$.

\section{Footnote 10 continued}

rates fall predominantly among young ages, crude birth rates might even increase slightly, without crucially affecting the overall pattern.

11 Acemoglu and Johnson (2007) show that considering a full adjustment of the capital stock only implies a larger effect of life expectancy on income per capita growth since the constraint of a fix factor of production is less binding. 
The population growth rate depends on the net rate of reproduction, which is given by the total (planned) fertility rate $n_{t}$ net of mortality up to fertile age, $1-p_{t}(\varphi)$. The mean age of reproduction (or mean length of a generation) is $\varphi$ while $p_{t}(\varphi)$ is the probability of surviving until $\varphi$. The fertility rate $n_{t}$ measures the number of children that would be born to an individual over her lifetime if that individual were to survive throughout her reproductive life, i.e., until $\varphi$. The net rate of reproduction can be approximated by $N R R_{t}=n_{t} p_{t}(\varphi) .^{12}$ An increase in life expectancy has two main effects on population size. First, lower mortality mechanically increases population size since more people survive at each point in time. ${ }^{13}$ In Acemoglu and Johnson (2007) this is reflected by the iso-elastic reduced form relationship $\ln p(\varphi)=\lambda \ln T_{t}$ with $\lambda>0$. Second, greater longevity may lead to changes in planned fertility. Following Fig. 1, assume that fertility initially does not react (or even slightly increases) in response to increasing life expectancy but eventually drops after the onset of the demographic transition. This change in fertility behavior, and consequently population growth, can be simply captured by considering an iso-elastic relationship also for fertility, with the elasticity depending on whether the country is pre- or post-transitional in terms of its demographic transition (FT): $\ln n_{t}=\ln b+x^{j} \ln T_{t}$ for $j=\{$ pre, post $\}$ with $x^{\text {pre }} \geq 0>x^{\text {post }}$ and $\left|x^{\text {post }}\right|>|\lambda|$, where $b>0$ represents factors that influence the level of fertility but are unrelated to life expectancy. The demographic transition is characterized by a reduction in fertility rates that more than compensates the mechanical effect on population size, which leads to a reduction in population growth rates in association with a reduction in mortality rates.

Using these expressions in (1), the level of log per capita income is therefore given by

$$
\ln y_{t}=\alpha \ln A_{t}+\alpha \ln h_{t}-(1-\alpha) \ln N_{t}+(1-\alpha) \ln L_{t}
$$

or

$$
\ln y_{t}=\pi^{j} \ln T_{t}+B_{t},
$$

where $B_{t}$ is a constant. ${ }^{14}$ The parameter of interest linking log per capita income to log life expectancy, $\pi^{j}$, is given by

$$
\pi^{j}=\alpha(\theta+\eta)-(1-\alpha)\left(x^{j}+\lambda\right) \gtrless 0,
$$

with $j=\{$ pre, post $\}$. Equation 4 illustrates the main source of ambiguity concerning the role of life expectancy for income per capita. The negative "population effect" $-(1-\alpha)\left(x^{\text {pre }}+\lambda\right)<0$ implies an ambiguous effect of life expectancy on income per

\footnotetext{
12 The net reproduction rate, $N R R$, is the average number of daughters that would be born to a woman if she survived through her fertile age and conformed to the age-specific fertility and mortality rates. Equivalently, the $N R R$ can be interpreted with reference to the whole population as the expected total number of children that the representative individual has during her fertile life. The specification used here, which neglects variations in age specific mortality for simplicity, is generally seen a good approximation of the net rate of reproduction, see also (Preston et al., 2001, p. 115).

13 A second, more indirect, mechanical effect arises if the likelihood of surviving until childbearing age increases. These effects are qualitatively identical but the direct effect has only temporary consequences, since it affects the level of population but not its long-run rate of growth (see Preston et al. 2001, pp. 158-159).

${ }^{14}$ Consider an initial period $t_{0}=0$ with $N_{0}$. Population at time $t>t_{0}$, after a period $\Delta t=t-t_{0}$, can then be expressed as $N_{t}=N_{0}\left[N R R \frac{\Delta t}{\varphi}\right]$ which is the linear version of the relationship between the population growth rate and $N R R$ in the Lotka stable population model (see Preston et al. 2001, p. 152). In one generation, $\Delta t=\varphi$, the population grows exactly by a factor $N R R$. Making use of the definition of $N R R$ and taking $\operatorname{logs}$, one can rewrite the condition as $\ln N_{t}=\left[\ln N_{0}+\ln (\Delta t / \varphi)+\ln b\right]+x^{j} \ln T_{t}+\lambda \ln T_{t}$, which implies that $B_{t}=(1-\alpha) \ln L_{t}+\alpha(\ln \bar{A}+\ln \bar{h})-(1-\alpha)\left(\ln N_{0}+\ln (\Delta t / \varphi)+\ln b\right)$.
} 
capita before the transition, $\pi^{\text {pre }} \gtrless 0$. After the transition, however, the effect is unambiguously positive, $\pi^{\text {post }}>0$, as population growth falls in response to improvements in life expectancy, such that $-(1-\alpha)\left(x^{\text {post }}+\lambda\right)>0$. As discussed above, this non-monotonicity is complemented by a successively lower reliance on fixed factors of production as the level of development improves, as well as by the possible acceleration in income per capita due to the changes in the age composition, the education attainment or labor force participation triggered by increases in life expectancy after the demographic transition. Extending the model to explicitly account for these mechanisms would leave the testable implications unchanged.

\subsection{Estimation framework}

Following Acemoglu and Johnson (2007), the main estimation framework can be derived directly from the theoretical illustration presented above. The estimation is in long differences, i.e., using panel data with only two observations per country, (1940 and 1980, or 1940 and 2000). ${ }^{15}$ Adding an error term, and separating countries $i$ by their demographic status $j=\{$ pre, post $\}$ as of 1940 , we can use condition (3) to derive the following estimation framework

$$
\ln y_{i t}^{j}=\pi^{j} \ln T_{i t}^{j}+\zeta_{i}^{j}+\mu_{t}^{j}+c^{j}+\varepsilon_{i t}^{j}
$$

for pre-transitional and post-transitional countries, respectively. The time invariant and country-specific components of the expressions that are functions of parameters are picked up by the country fixed effects $\zeta_{i}$, while time varying factors which are common to the different (groups of) countries are picked up by time fixed effects, $\mu^{j}$. The common time dummy controls for global changes in the main variables of interest over the observation period, which are similar across countries of group $j=\{$ pre, post $\}$. The coefficients $\pi^{\text {pre }}$ and $\pi^{\text {post }}$ are the respective parameters of interest. As in Acemoglu and Johnson (2007), the consideration of a long-difference regression with two observations per country with $t=\{0,1\}$ implies that the estimation of the previous equations is equivalent to the estimation of the first-difference specification

$$
\Delta \ln y_{i}^{j}=\pi^{j} \Delta \ln T_{i}^{j}+\Delta \mu^{j}+u_{i}^{j},
$$

where $\Delta \ln y_{i}^{j}=y_{i 1}^{j}-y_{i 0}^{j}$ and $\Delta \ln T^{j} \equiv \ln T_{1}^{j}-\ln T_{0}^{j}$. Note that, in principle one might or might not allow for differential time trends, $\Delta \mu^{\text {pre }}$ and $\Delta \mu^{\text {post }}$, across pre-transitional and post-transitional countries. Allowing for two distinct time trends, $\Delta \mu^{\text {pre }}$ and $\Delta \mu^{\text {post }}$ as in Eq. 5, implies estimating a fully-interacted model. ${ }^{16}$ This model is equivalent to estimating the specification of Acemoglu and Johnson (2007) separately for pre-transitional and post-transitional countries. Restricting the time trend to be the same for pre-transitional and post-transitional countries, $\Delta \mu^{\text {pre }}=\Delta \mu^{\text {post }}$, implies estimating a semi-interacted model that only allows for a differential effect in terms of $\pi$ in pre-transitional and post-transitional

\footnotetext{
15 The choice of a forty years horizon is justified by the fact that changes in fertility behavior and population are likely to take place over the course of generations and, therefore, need a sufficiently long observation period to become effective and detectable. Changes in life expectancy that take place at some point in time after 1940 may affect fertility in the following decades and should be captured by 1980 or 2000, but potentially not before.

16 Note that the size of the time trend $\Delta \mu^{j}$ also depends on the time interval, that is the term $-(1-\alpha)\left[\ln \left(\Delta t_{2}\right)-\ln \left(\Delta t_{1}\right)\right]$ which results from taking first differences, where $\Delta t_{2} \equiv t_{2}-t_{0}$ and $\Delta t_{1} \equiv t_{1}-t_{0}$, where $t_{0}=1940, t_{1}=1980$ and $t_{2}=2000$, regardless of whether estimating a common time effect or allowing for different time effects in both pre-transitional and post-transitional countries.
} 
countries. ${ }^{17}$ Below we will investigate both alternatives. Recall that from Fig. 2 and the theory above, we expect $\pi^{\text {pre }} \gtrless 0$ and $\pi^{\text {post }}>0$. Recall also that if total fertility $n$ were assumed to be constant or unrelated to life expectancy, then

$$
\pi^{\text {pre }}=\pi^{\text {post }}=\pi=\alpha(\theta+\eta)-(1-\alpha) \lambda \gtrless 0 .
$$

This coincides with the coefficient estimated by Acemoglu and Johnson (2007), which means that their model is nested in the specification above, and which therefore allows for testing the equality of coefficients obtained with pre-transitional and post-transitional samples.

\section{Data and identification strategy}

The main outcome variables are GDP per capita and population size; the main explanatory variable is life expectancy at birth. The essential data sources are the UN Demographic Yearbook, and Maddison (2003), see also Acemoglu and Johnson (2007) for details. The base sample consists of 47 countries for which all relevant data on life expectancy and the outcome variables, as well as on the on the predicted mortality instrument that is used to identify causal effects, are available for 1940 and 1980 (or 2000).

\subsection{The empirics of the demographic transition}

The demography literature has proposed several criteria to identify whether a country has reached the critical turning point of the demographic transition in light of the stylized facts reported in Fig. 1, see e.g., (Chesnais, 1992, p. 19):

\section{$\mathrm{C} 1$ Life expectancy at birth exceeds 50 years;}

C2 Fertility or the crude birth rate has exhibited a sustained decline;

C3 The crude birth rate has fallen below the threshold of 30/1000.

The first criterion implies that a country enters the demographic transition when mortality is sufficiently low. The conventional threshold for life expectancy at birth is taken to be 50 years. Second, the fertility transition can be identified by a sustained decline in total fertility or crude birth rates. Third, a country is considered post-transitional if the crude birth rate is sufficiently low, and in particular below 30 births per 1000 inhabitants. ${ }^{18}$ In the empirical application we call a country post-transitional or pre-transitional depending on whether it satisfies these criteria by 1940 or not, respectively. Ideally, one would take into account

17 The semi-interacted model follows from an estimation framework

$$
\ln y_{i t}=\pi^{\text {pre }} \ln T_{i t}+\pi^{\text {post }} \ln T_{i t} \cdot \text { Post }_{i}+\zeta_{i}+\text { Post }_{i}+\mu_{t}+c+\varepsilon_{i t}
$$

where the level of demographic development is indicated by the time-invariant binary indicator Post $t_{i}$, which takes value 1 if a country is classified as post-transitional by 1940, and zero otherwise. Notice that this indicator is not identified in levels due to the inclusion of country fixed effects. Taking long differences then delivers as estimation equation

$$
\Delta \ln y_{i}=\pi^{\text {pre }} \Delta \ln T_{i}+\pi^{\text {post }} \Delta \ln T \cdot \text { Post }_{i}+\Delta \mu+u_{i}^{j}
$$

in which, in contrast to (6), the time trend $\Delta \mu$ is not allowed to vary by demographic status $j=\{$ pre, post $\}$. 18 The first criterion is expected to be, on average, the least restrictive one in defining post-transitional countries because the drop in mortality usually precedes the drop in fertility. The second criterion is less restrictive than the third criterion since it classifies a country as post-transitional when the sustained fertility reduction has started although the process may not be complete (so that the crude birth rate may be still above 30/1000). 
whether the country experiences an exogenous change in life expectancy while it is still pretransitional, or already post-transitional, at the time of treatment. However, the data using the epidemiological revolution to construct the predicted mortality instrument used in the analysis below only contain country-specific information for the predicted change in mortality over the full period. We therefore consider a classification of countries into pre-transitional and post-transitional as of 1940, i.e., before the treatment in terms of the mortality reduction due to the epidemiological revolution. In the sample of Acemoglu and Johnson (2007), the application of each of the three different criteria leads to the same classification and delivers 25 pre-transitional and 22 post-transitional countries in $1940 .{ }^{19}$

We apply the three classification criteria also in 1980 (and 2000). This allows us to distinguish countries that entered the demographic transition during the observation period 19401980 (and 1940-2000), from countries that remained fully pre-transitional throughout the observation period. We use these classifications to investigate the hypothesis that reductions in mortality facilitate the demographic transition in the countries that are still pre-transitional in 1940. As expected, all post-transitional countries in 1940 remain post-transitional during the entire observation period, while some previously pre-transitional countries undergo the demographic transition after $1940 .{ }^{20}$ Finally, for comparability, we also apply the classification of Acemoglu and Johnson (2007) according to which countries are grouped by initial income in 1940 (rich and non-rich countries). This classification can be justified by the fact that the economic and demographic transitions tend to be closely related. It is important to notice, however, that this classification does not directly relate to the theoretical argument based on the demographic transition presented above.

\subsection{Preliminary analysis}

Table 1 presents the descriptive statistics. Average life expectancy at birth in 1940 is 49.3 in the full sample but is 38.8 and 61.2 years in pre- and post-transitional countries, respectively. The respective average crude birth rates (CBR) in the two groups were 45.3 and 20.4. By 1980 life expectancy increased to 62.3 and 73.7 while the CBR dropped to 32.5 and 14.1, respectively. Figure 3 depicts the levels of log life expectancy and crude birth rates for all countries in the years 1940,1960, 1980 and 2000. There are two clearly distinct groups of countries, with countries that are pre-transitional in 1940 displaying the largest increases in life expectancy and the largest reductions in the CBR. The changes in the CBR are negative for all countries with the largest reductions being observed for the countries with intermediate increases in life expectancy. ${ }^{21}$ These patterns are consistent with those emerging from Fig. 1.

\footnotetext{
19 To verify the second criterion we follow Reher (2004) and consider a country to be post-transitional if it has entered the falling trend in terms of the 5-year averages of crude birth rates by the year 1935 . His classification coincides with the second criterion with the exceptions of Greece, Ireland and New Zealand, which are not classified in Reher (2004). In the case of Greece the problem is the lack of reliable data before 1950. Ireland and New Zealand display a very flat profile of crude birth rates around 30/1000 after 1940 and a clear drop only in 1980 and 1960 respectively. In our baseline classification we consider these three countries as post-transitional in 1940 since they clearly satisfy criteria $C 1$ and $C 3$. The robustness of the results, is checked by applying alternative criteria as discussed in details in the Online Appendix. This Appendix also presents a table that summarizes the different classifications, and a figure that provides a graphical illustration of the demographic dynamics underlying these criteria by depicting the crude birth rates of all 47 countries in the sample over the period 1940-2000.

20 A table that reports the baseline classification of the countries into post-transitional, intermediate (undergoing the transition between 1940 and 1980), and pre-transitional throughout 1940-1980, together with the two robustness classifications can be found in the Online Appendix.

21 The countries with initial life expectancy close to 50 years are closest to the onset of the transition and, accordingly experience the largest cumulative reductions in fertility, see also Fig. 11 in the Online Appendix.
} 
Table 1 Descriptive statistics

\begin{tabular}{|c|c|c|c|c|c|c|c|}
\hline & \multirow[t]{2}{*}{ Year } & \multicolumn{2}{|c|}{ Base sample } & \multicolumn{2}{|c|}{ Pre-transitional countries } & \multicolumn{2}{|c|}{ Post-transitional countries } \\
\hline & & Mean & SD & Mean & SD & Mean & SD \\
\hline \multirow[t]{3}{*}{ Life expectancy at birth } & 1940 & 49.3 & 12.7 & 38.8 & 6.17 & 61.2 & 5.38 \\
\hline & 1980 & 67.6 & 7.41 & 62.3 & 6.25 & 73.7 & 1.70 \\
\hline & 2000 & 72.9 & 5.46 & 69.1 & 4.65 & 77.4 & 1.55 \\
\hline Predicted mortality & 1940 & 0.47 & 0.28 & 0.65 & 0.23 & 0.27 & 0.17 \\
\hline \multirow[t]{3}{*}{ Log GDP per capita } & 1940 & 7.74 & 0.73 & 7.21 & 0.50 & 8.34 & 0.39 \\
\hline & 1980 & 8.62 & 0.95 & 7.91 & 0.72 & 9.44 & 0.29 \\
\hline & 2000 & 8.96 & 0.96 & 8.22 & 0.68 & 9.81 & 0.32 \\
\hline \multirow[t]{3}{*}{ Log population } & 1940 & 9.11 & 1.53 & 9.03 & 1.80 & 9.20 & 1.20 \\
\hline & 1980 & 9.81 & 1.48 & 10.0 & 1.68 & 9.55 & 1.20 \\
\hline & 2000 & 10.1 & 1.49 & 10.4 & 1.63 & 9.67 & 1.21 \\
\hline \multirow[t]{3}{*}{ Log GDP } & 1940 & 9.94 & 1.59 & 9.34 & 1.58 & 10.6 & 1.32 \\
\hline & 1980 & 11.5 & 1.49 & 11.0 & 1.49 & 12.1 & 1.31 \\
\hline & 2000 & 12.1 & 1.55 & 11.8 & 1.68 & 12.6 & 1.30 \\
\hline \multirow[t]{3}{*}{ Crude birth rate } & 1940 & 33.6 & 13.2 & 45.3 & 4.17 & 20.4 & 3.70 \\
\hline & 1980 & 23.9 & 10.7 & 32.5 & 6.57 & 14.1 & 3.27 \\
\hline & 2000 & 17.5 & 6.86 & 22.4 & 5.63 & 11.9 & 2.37 \\
\hline
\end{tabular}

Sample sizes are 47 countries in the base sample, 25 pre-transitional countries and 22 post-transitional countries. The classification follows criteria 1, 2 and 3 described in the text

To gain a further visual impression, we illustrate the dynamic evolution of the average crude death rates, crude birth rates and natural rate of population growth in the two groups of countries. Figure $4 \mathrm{a}$ depicts the variables for the countries which are already post-transitional before 1940. Crude death rates are about 12/1000 in 1940, decline by about $25 \%$ until 1960 , and stabilize afterwards. ${ }^{22}$ The crude birth rate and the net rate of population growth decline by about $50 \%$ by 1980 and keep decreasing until year 2000 . Figure $4 \mathrm{~b}$ plots the respective series for countries which are still pre-transitional in 1940. For these countries, the average crude death rate in 1940, which is around 20/1000, shows a clear negative trend. Death rates are reduced by about $50 \%$ in 1970 when they reach 10/1000, which is about the average death rate of post-transitional countries in 1940 . After 1970, death rates drop by about $20 \%$ in the next twenty years and eventually stabilize. The crude birth rate is essentially unchanged until 1960 and displays a sizable decline only after 1970. Accordingly, the natural rate of population growth is initially increasing and displays a sustained decline only after 1970. By 1990, the natural population growth rate is still about the same as in 1940. Figure 4 illustrates the different phases of the demographic transition as empirical counterpart to Fig. 1. Reductions in mortality breed larger population growth until the onset of the demographic transition, but this trend is reversed afterwards and turns negative for post-transitional countries. It is noteworthy that only after 1970 the time series of pre-transitional countries resemble those of countries which are already post-transitional in 1940.

Figure 5 depicts the change in log population from 1940 to 1980 (panel a), and from 1940 to 2000 (panel b) against the change in log life expectancy at birth over the respective period.

22 Life expectancy at birth keeps increasing although the crude death rate stabilizes due to the increase in the share of elderly in these countries. The shaded area represents $95 \%$ confidence intervals. 


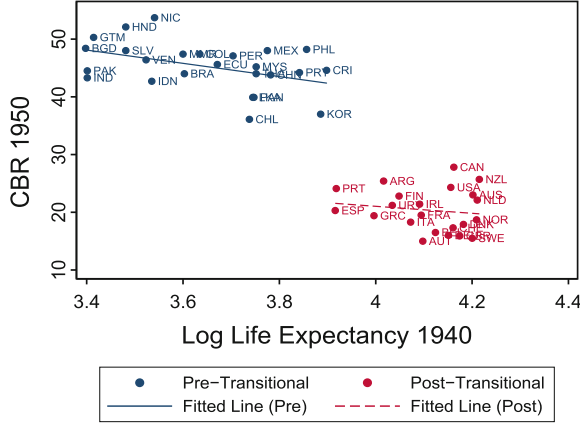

(a) Crude Birth Rate 1940

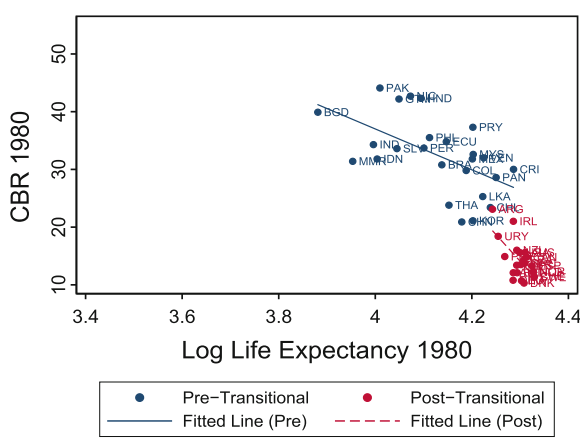

(c) Crude Birth Rate 1980

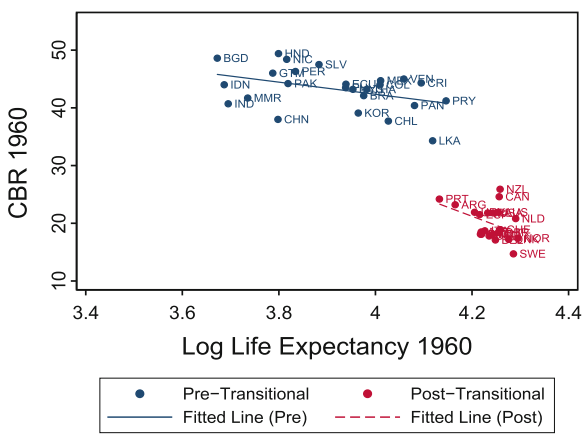

(b) Crude Birth Rate 1960

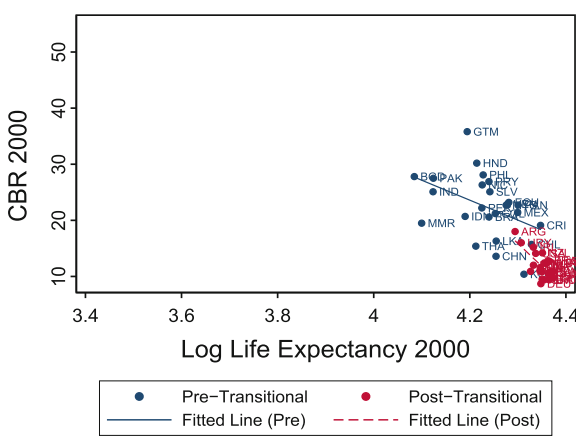

(d) Crude Birth Rate 2000

Fig. 3 Life expectancy and crude birth rates for the years a 1940, b 1960, c 1980 and d 2000. Classification according to criteria 1, 2, 3, see Table 6 (Appendix Online) and main text for detailed description of the classification criteria. Data source: UN population statistics

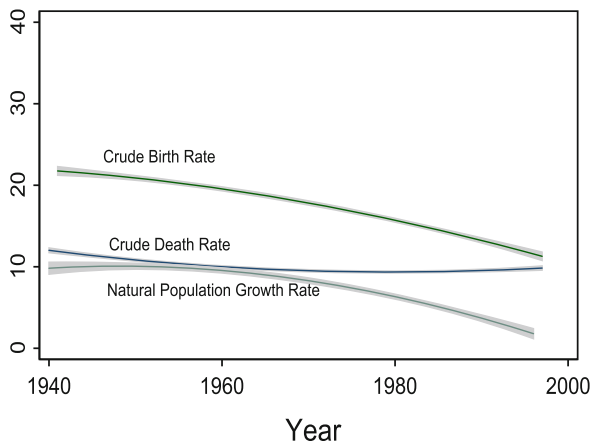

(a)

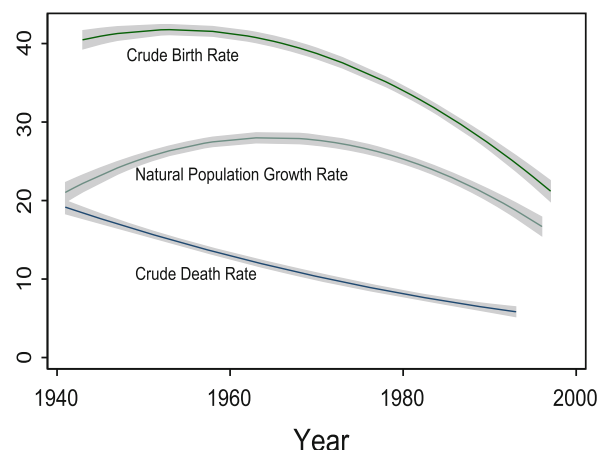

(b)

Fig. 4 Demographic dynamics in a post-transitional and b pre-transitional countries. Average evolution of crude birth, death and natural population growth rates. Classification according to criteria 1, 2, 3, see Table 6 (Appendix Online) and main text for detailed description of the classification criteria

Panels (c) and (d) show the corresponding graphs for the relationship between the change in log GDP per capita and changes in life expectancy. Considering the pooled sample, the figures show a clear positive relationship between changes in life expectancy and population growth, and a clear negative relationship between changes in life expectancy and GDP per 


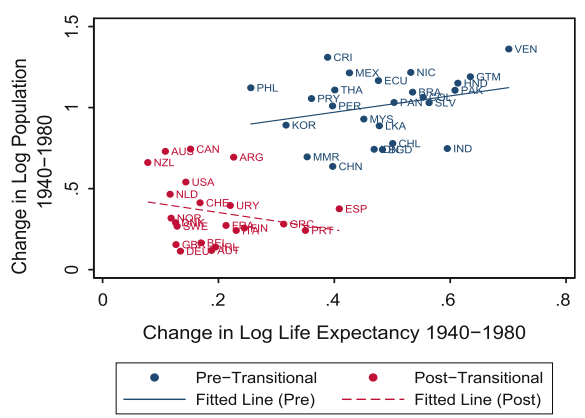

(a)

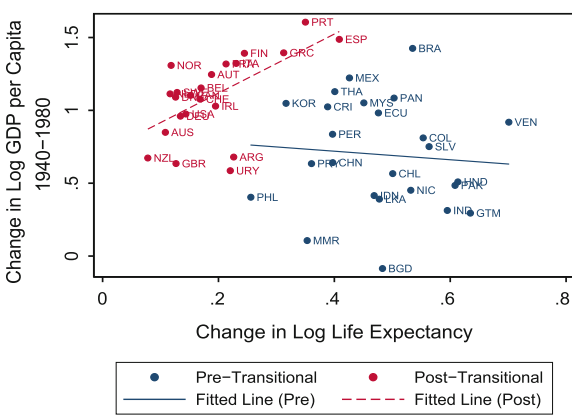

(c)

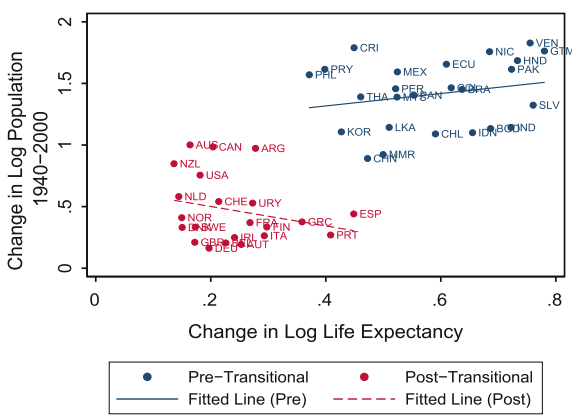

(b)

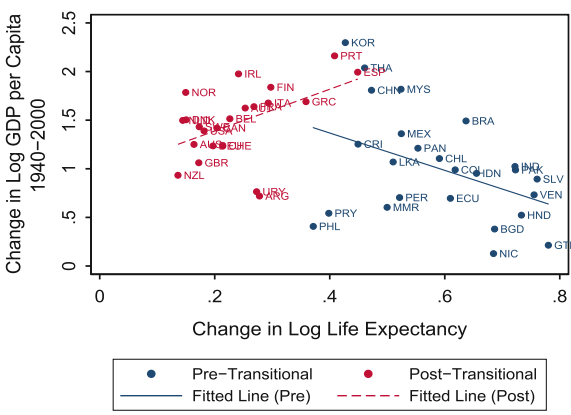

(d)

Fig. 5 The consequences of the demographic transition for development. a Change in log life expectancy and change in log population 1940-1980. b Change in log life expectancy and change in log population 1940-2000. c Change in log life expectancy and change in log GDP per capita 1940-1980. d Change in log life expectancy and change in log GDP per capita 1940-2000. Changes in log life expectancy on the changes in GDP per capita and population. Classification according to criteria 1, 2, 3, see Table 6 (Online Appendix) and main text for detailed description of the classification criteria

capita growth. Due to the estimation framework in long differences with country and year fixed effects, this is essentially the variation that identifies the effect of interest in the study by Acemoglu and Johnson (2007). However, in line with Fig. 1 the effect on population growth rates differs in pre-transitional and post-transitional countries. The figure shows two separate groups of countries, one characterized by small changes in population and life expectancy, and the other by large changes, with different effects of life expectancy within each of these two groups. When considering the additional information in Fig. 5 by investigating separately pre-transitional and post-transitional countries, it appears that pre-transitional countries experienced larger increases in life expectancy, but were associated with a lower growth in GDP per capita. In contrast, in post-transitional countries, larger improvements in life expectancy were associated with faster growth in income per capita. In this context it is worth noting that the different slopes also imply different intercepts, which essentially capture different conditional time trends in population and income growth across the two subgroups of countries. 


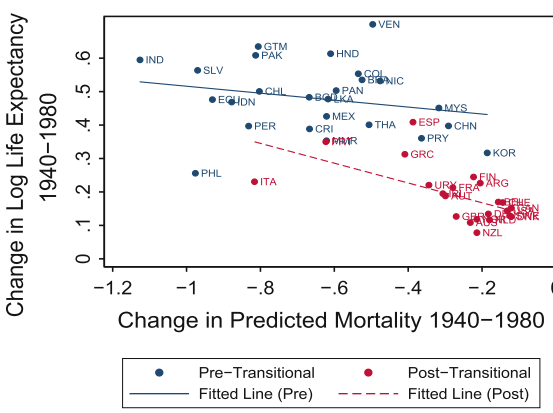

(a)

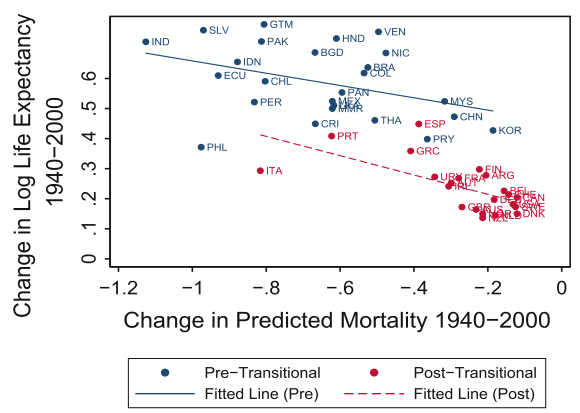

(b)

Fig. 6 Predicted mortality changes and changes in life expectancy (a 1940-1980, b 1940-2000). Classification according to criteria 1, 2, 3, see Table 6 (Online Appendix) and main text for detailed description of the classification criteria.

\subsection{Identification strategies}

We use the predicted mortality instrument proposed by Acemoglu and Johnson (2007) as benchmark to identify the causal effects of life expectancy. This instrument exploits information on the reduction in mortality due to the epidemiological revolution. The instrument for the change in life expectancy is the reduction in mortality from 15 of the most important infectious diseases following the epidemiological transition in the 1940s. Three components of the epidemiological transition motivate this instrument: the wave of drug and chemical innovations that led to effective vaccines and medicines for major diseases (like antibiotics to treat the diseases, or chemicals like DDT to eradicate their transmission vectors); the establishment of international institutions like the WHO or UNICEF that facilitated the distribution of medical and public health technology; and, finally, the change in international values leading to a fast dissemination of medical knowledge. The validity of this instrument relies on the assumption that the exclusion restriction holds, namely that the instrument is exogenous to a particular country's level of economic development and does not affect income or population through other channels than life expectancy. This requires, in particular, that mortality from these diseases is exogenous for lack of appropriate treatments in 1940, and due to the worldwide dissemination of treatment and prevention by $1980 .^{23}$

Figure 6 illustrates the relationship between the predicted mortality reductions due to the epidemiological transition, and the changes in life expectancy. Larger absolute reductions in predicted mortality are associated with larger changes in life expectancy in both pre-transitional and post-transitional countries. Notice that the predicted mortality variable implies that a more negative realization (a larger drop in mortality) is associated with a larger increase in life expectancy. This is a first indication that the instrument appears to be relevant for all countries as expected from the extensive analysis of Acemoglu and Johnson (2007). Figure 7 depicts the change in log population and GDP per capita from 1940 to 1980 (left panels) and from 1940 to 2000 (right panels), against the predicted mortality reduction due to the

23 Essentially, the exclusion restriction in Acemoglu and Johnson (2007) is based on the view that no treatment or vaccine existed worldwide for the respective diseases captured by the mortality instrument as of 1940, such that the mortality due to these diseases entirely depended on country-specific features that are unrelated to the error term in the growth regression. The exclusion restriction also assumes that mortality from these diseases dropped in all countries independently of their economic development due to the nature of the epidemiological transition, i.e., due to the discovery and the world-wide dissemination of drugs and vaccines. 

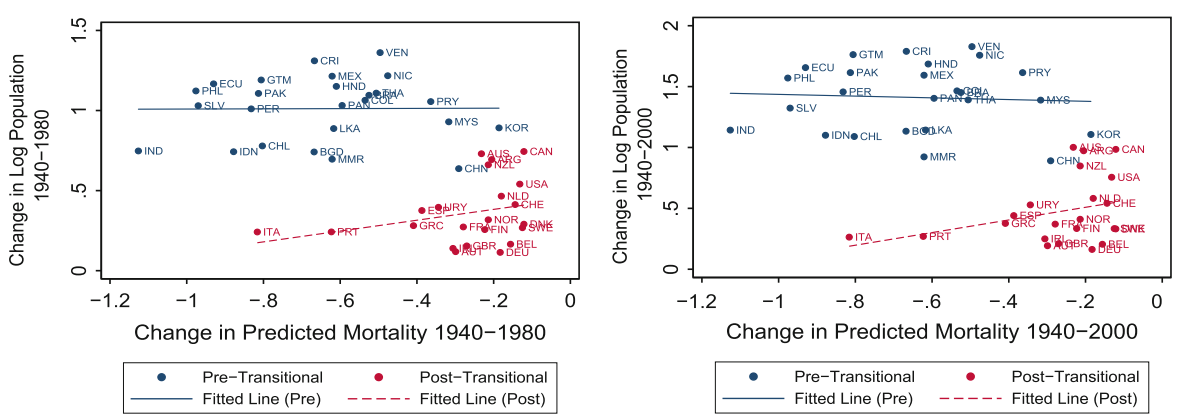

(a)

(b)

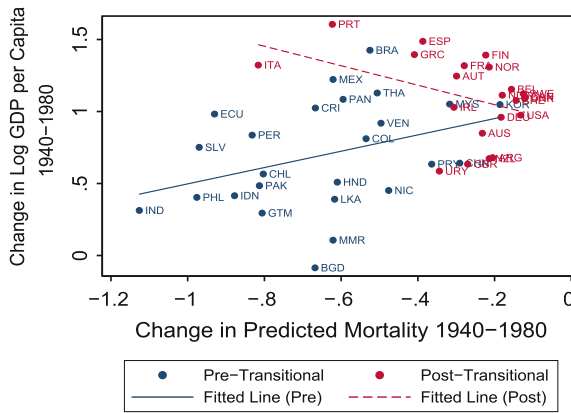

(c)

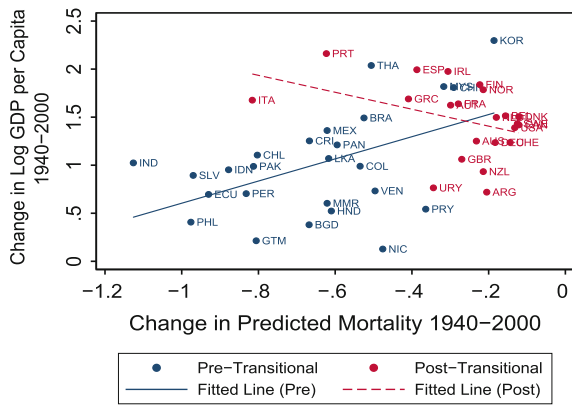

(d)

Fig. 7 Predicted mortality changes and changes in income and population. a Change in log population 19401980. b Change in log population 1940-2000. c Change in log GDP per capita 1940-1980. d Change in log GDP per Capita 1940-2000. Effect of changes in predicted mortality changes (instrument by Acemoglu and Johnson (2007) on changes in income per capita and population. Classification according to criteria 1, 2, 3, see Table 6 (Online Appendix) and main text.

epidemiological transition. This figure complements Fig. 5 in showing that log population is decreasing with predicted mortality reductions in post-transitional countries, while population growth is accelerated in pre-transitional countries, as can be seen in Panels (a) and (b). In fact, similar to the pattern shown in Fig. 3, the largest reductions in mortality occur in pre-transitional countries with the largest levels of crude birth rates, so that the result is an initial increase in population growth. The differential effect of life expectancy on population growth in pre-transitional and post-transitional countries is larger over the longer time horizon as illustrated in Panel (b). Panels (c) and (d) of Figs. 5 and 7 show that the changes in $\log$ GDP per capita are large and increasing in predicted mortality in post-transitional countries, while they are lower and decreasing in predicted mortality in pre-transitional countries over both time horizons.

The hypothesis of a non-monotonic effect of life expectancy on growth is based on theoretical considerations in light of demographic transition theory, and should therefore not rely on a particular identification or estimation strategy. In fact, it is not clear to which extent endogeneity problems of income on life expectancy should affect the predicted non-monotonicity in the relation between life expectancy and income. We therefore also present the corresponding OLS results when accounting for the possibility of heterogeneous effects of life expectancy. Given the debate about the seemingly contradictory findings in the literature that have been obtained using identifying variation across and between countries, we also present estimates 
that use as an alternative identification strategy the instrumentation proposed by Lorentzen et al. (2008). Their approach exploits cross-country variation in the health environment as measured by a malaria ecology index, as well as 12 Koeppen-Geiger climate zones, mean distance of centroid from coast, mean latitude of centroid, mean elevation and log country area in square kilometers. ${ }^{24}$

\section{Causal effect of life expectancy on income growth}

This section tests the hypothesis that the causal effect of life expectancy on income growth is different for different levels of demographic development. We first estimate models that account for the status of countries as pre- or post-transitional as of 1940 based on the information presented in Sect. 3, in order to test whether the effect is significantly different across pre-transitional and post-transitional countries. In light of the typical pattern of the demographic transition, we also test the hypothesis that improvements in life expectancy increases the likelihood of observing the onset of the demographic transition. In addition, we perform a series of robustness checks.

\subsection{Causal effects in pre- and post-transitional countries}

Table 2 presents the main results regarding the causal effect of life expectancy for GDP per capita, using information for the period 1940-1980 in Panel (A) and for 1940-2000 in Panel (B). Column (1) replicates the analysis by Acemoglu and Johnson (2007). The average effect of an increase in life expectancy, instrumented by predicted mortality reductions, on income per capita is significantly negative. The explanation for this finding can be seen in the respective column of Table 3, which contains the corresponding results for population growth as dependent variable and shows a significant positive effect of increases in life expectancy on population growth. We test for neglected non-linearities applying RESET test methods, see Pesaran and Taylor (1999) and Wooldridge (2002, p. 124-125). These tests indicate that the null of no neglected non-linearities is generally rejected over the period 1940-1980: the null is rejected against an alternative of a non-linear specification with a quadratic (cubic) polynomial in the case of population with $p$-values of $0.046(0.017)$, and with $p$-values of $0.538(0.012)$ in the case of GDP per capita. ${ }^{25}$

The causal effect of life expectancy for pre- and post-transitional countries is investigated using both the partially and the fully interacted model. We consider both specifications since the partially interacted model is more efficient but also more restrictive. ${ }^{26}$ Recall that the classification of countries is pre-treatment in terms of the predicted mortality instrument since it refers to the period pre 1940 and is time invariant. The differential effect of changes

\footnotetext{
${ }^{24}$ The malaria ecology index combines "climatic factors and the presence of different mosquito vector types and human biting rates of different mosquito vectors", see Lorentzen et al. (2008) and Sachs et al. (2004) for details.

25 The respective $p$-values for the period 1940-2000 are 0.057 (0.048) for population and $0.693(0.460)$ for GDP per capita. The non-linearities appear to be even stronger in the OLS specifications with log life expectancy or the predicted mortality instrument as explanatory variables, where the null is typically rejected on the 5\% level. Finally, unreported RESET tests do not reject the null of no neglected non-linearities for aggregate GDP growth in any specification. The effect of life expectancy on aggregate GDP growth is therefore approximately linear, and, as found by Acemoglu and Johnson (2007), positive but small. Detailed results are presented in Table 8 in the Online Appendix.

26 As shown before, the partially interacted model involves the estimation of only one common time effect on the full sample but, in view of (6), it imposes the restriction that $\Delta \mu_{t}^{\text {pre }}=\Delta \mu_{t}^{\text {post }}$.
} 


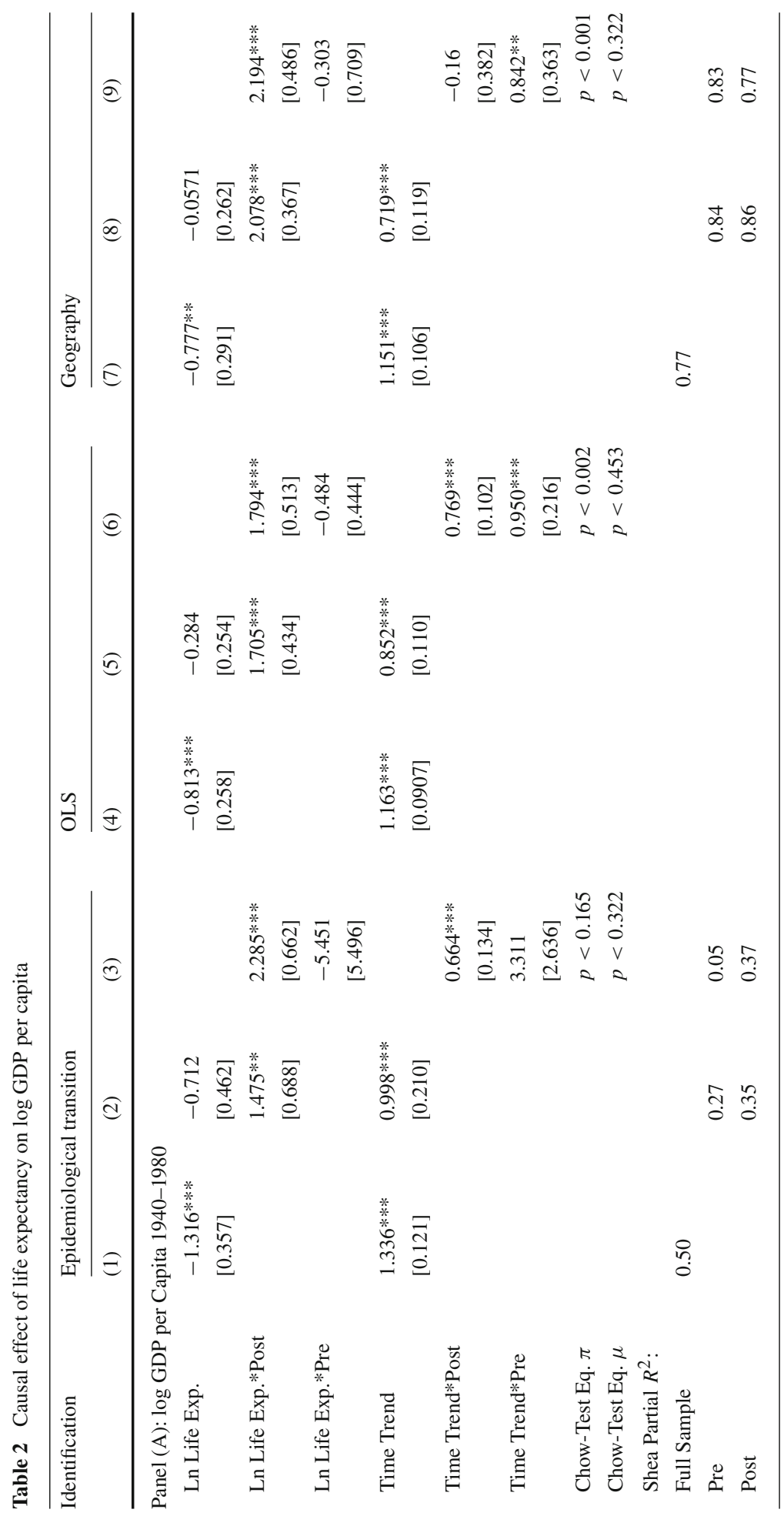




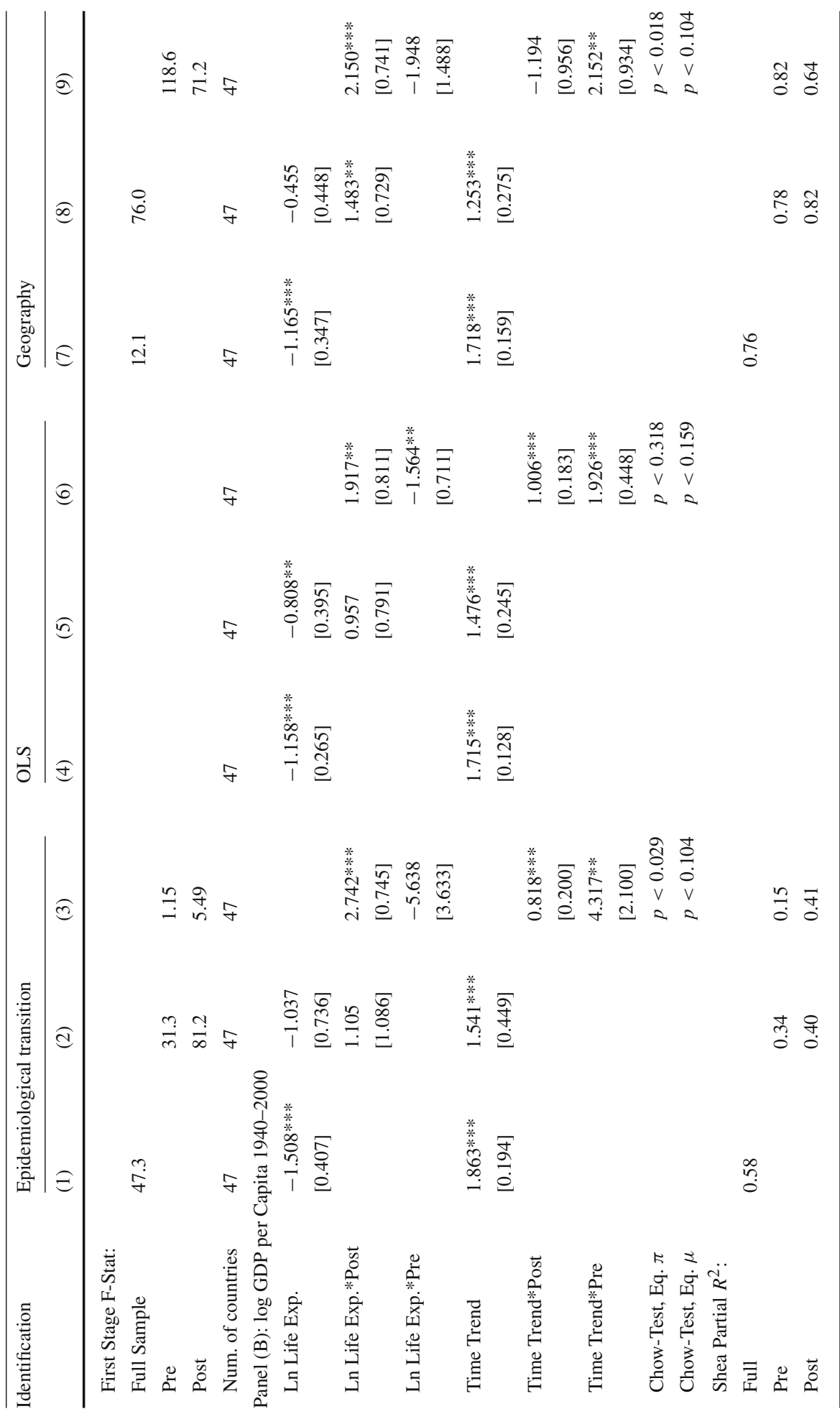




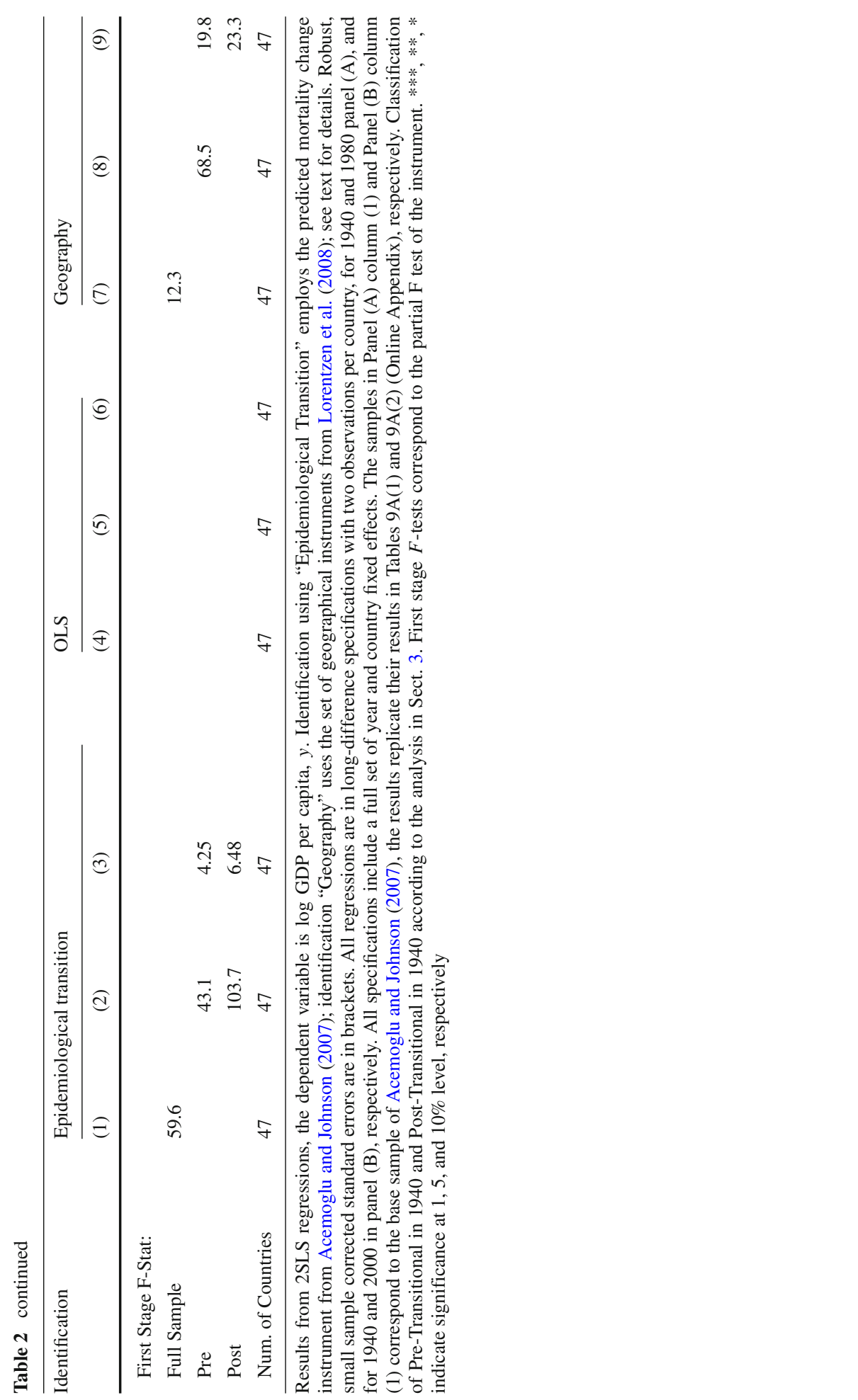




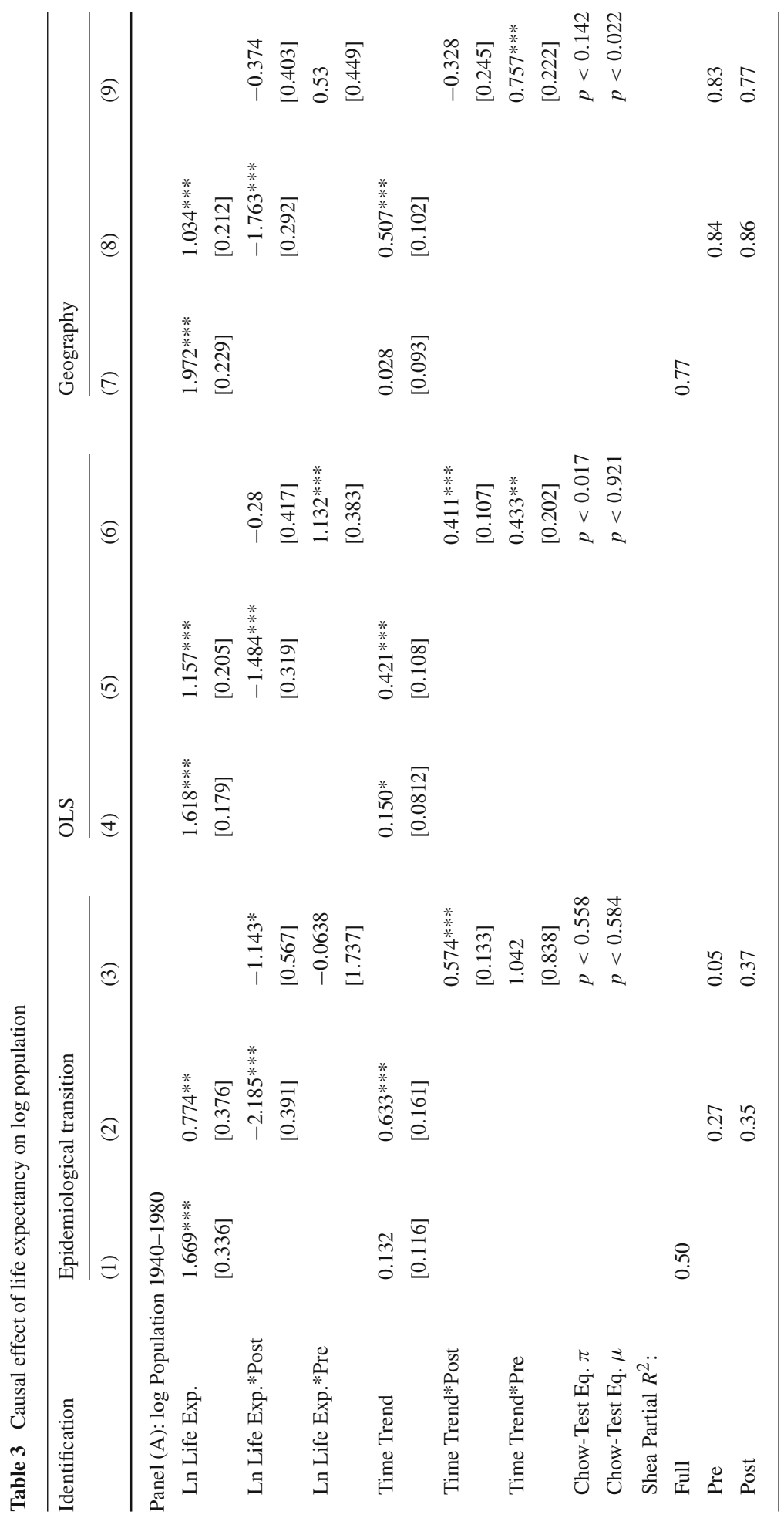




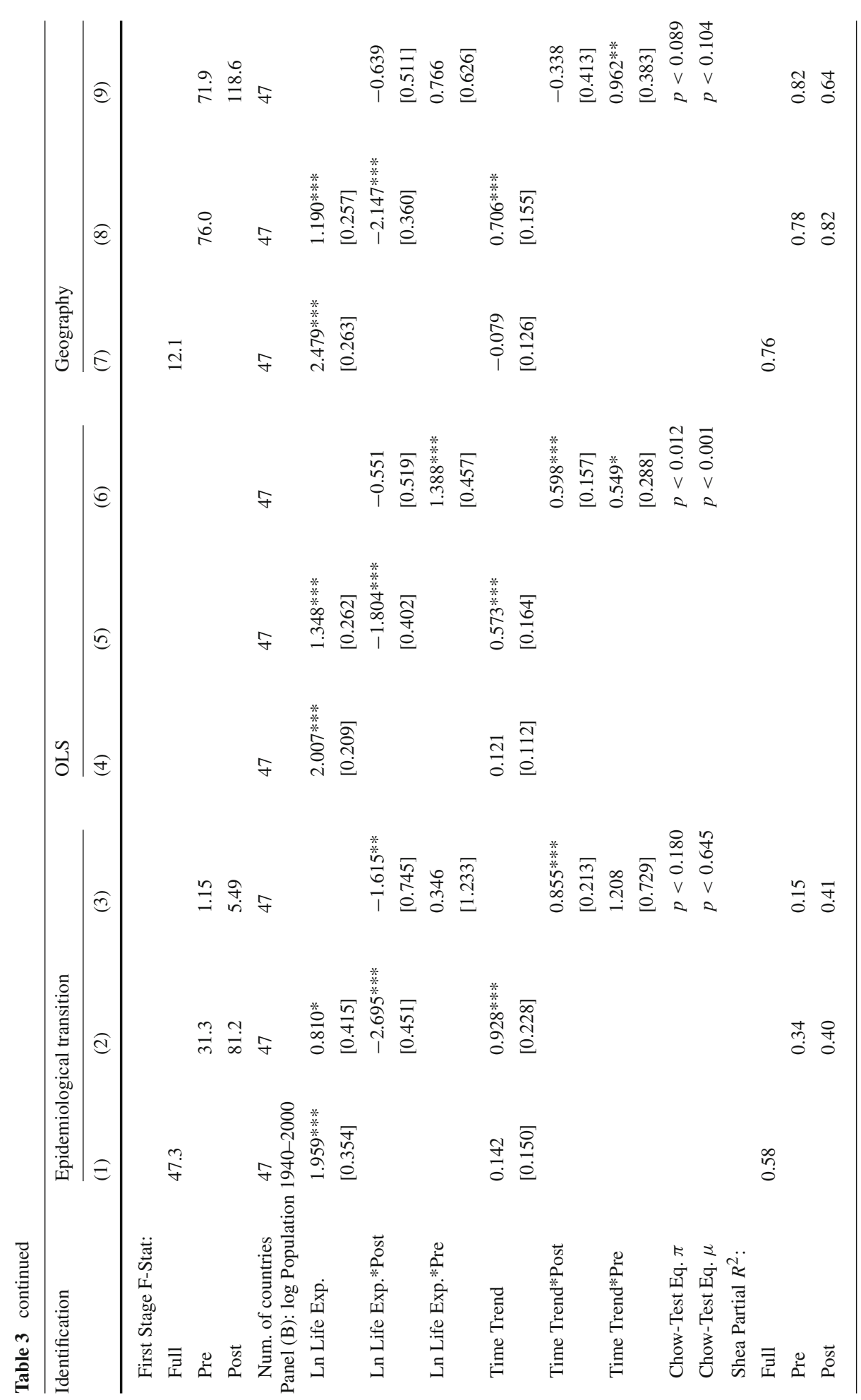




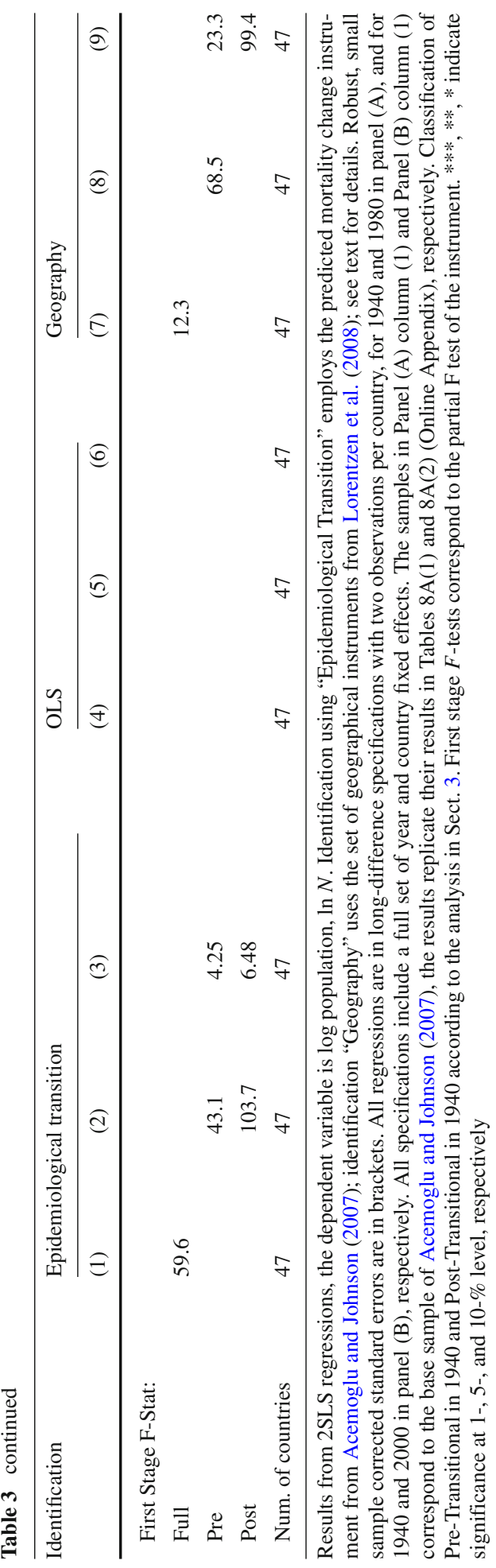


in mortality in the partially interacted model is therefore captured by including an interaction between changes in log life expectancy and the dummy that identifies the countries as pre- or post-transitional. The corresponding estimation results of the differential effect of changes in life expectancy on income per capita growth over the period 1940-1980 are reported in column (2) of Table 2. The effect of life expectancy on income per capita is negative for pre-transitional but positive and significant for post-transitional countries. ${ }^{27}$ The results for the fully interacted model, reported in columns (3), are qualitatively identical. In line with the hypothesis, these results suggest that the effect of improvements in life expectancy on per capita income growth differs substantially between pre-transitional and post-transitional countries, with a negative insignificant effect for pre-transitional and a positive significant effect for post-transitional countries. The point estimates are larger in size in the fully interacted model, with a causal effect of life expectancy on income that is almost twice as large, but of the opposite sign, compared to the average effect obtained with the pooled sample. This result is complemented by a causal effect with opposite signs on population growth, as can be seen from the corresponding columns in Table 3 .

The bottom part of Tables 2 and 3 presents test statistics for the first stage performance of the instrument (F-statistics of excluded instruments and Shea's partial R-square statistics). As a consequence of the smaller sample sizes in the fully interacted model (which is equivalent to splitting the sample), the first stage partial $\mathrm{F}$ of the instrument becomes smaller, but, by and large, the instrument performs fairly well, as was to be expected already from the extensive tests provided by Acemoglu and Johnson (2007). The Shea's partial R-square statistic is also reasonably high, usually around 0.3 or above, indicating that the instrument explains a substantial part of the variation in the instrumented variable.

The results from OLS estimates are presented in columns (4), (5) and (6) of Tables 2 and 3. The OLS estimates deliver coefficients that are of the same sign as the IV estimates and that are slightly smaller in absolute magnitude across all specifications. ${ }^{28}$ The differences between OLS and IV results tend to be larger for pre-transitional countries. This is confirmed by Hausman-type endogeneity tests that reject the null of exogeneity of log life expectancy in the pooled sample and in the pre-transitional samples. However, the null of exogeneity cannot be rejected for the samples of post-transitional countries. One possible explanation for this finding is that life expectancy is measured with larger error in pre-transitional countries, in particular as of 1940. In this context, the instrumentation might help reducing the incidence of attenuation bias particularly in this sample, as is suggested by the larger discrepancies between OLS and IV results for pre-transitional countries. ${ }^{29}$ This does not affect the finding of different signs of the causal effect for pre-transitional and post-transitional countries, but suggests, if anything, that the estimates are more reliable for post-transitional countries.

To investigate the role of the different instrumentation strategies, we replicate the analysis by using the instruments suggested by Lorentzen et al. (2008) instead of Acemoglu and Johnson's predicted mortality change instrument. In the present context of two observations by

\footnotetext{
27 Recall that, since the effect is presented in terms of an interaction with a dummy, the effect for the post transitional countries is given by the sum of the two coefficients.

28 We also repeated the whole analysis with in an intention to treat specification using the predicted mortality instrument rather than log life expectancy as regressor of interest. The results are qualitatively identical and are available upon request.

29 On this point see also (Lorentzen et al., 2008, p. 103). The vital statistics on which life tables are based are often incomplete or missing. These measurement and registration problems are particularly severe in countries where the vital registration system is deficient, where a sizable proportion of the population has never attended school, or in countries where infant mortality is very high, see, e.g., (United Nations, 1983, p.2). As consequence, errors associated with the indirect projection measures that are used to produce life tables might be more severe in developing countries, i.e., countries that are pre-transitional as of 1940 .
} 
country and considerable convergence in life expectancy, the change in life expectancy and the initial level of life expectancy contain very similar information. In fact, the correlation between log life expectancy in 1940 and the change in log life expectancy over the period $1940-1980$ is -0.95 , and -0.98 over the period 1940-2000. Moreover, the logic behind this instrument is similar to the Acemoglu and Johnson's predicted mortality instrument, which essentially exploits cross-country variation in mortality in 1940 from the particular diseases, while assuming that this mortality has been reduced to zero in all countries by 1980 . Consequently, the set of instruments proposed by Lorentzen et al. (2008) appears valid for changes in life expectancy in the application under consideration. The respective results are reported in columns (7), (8) and (9) of Tables 2 and 3. These results are qualitatively identical to the results obtained with the instrumentation of Acemoglu and Johnson (2007). In particular, as with the predicted mortality instrument, the effect of life expectancy on income per capita is negative (although lower in magnitude) with the linear specification in the full sample. The results change once the constraint that the effect must be the same for all countries is removed, however. The effect of life expectancy on growth is non-monotonic with respect to the demographic status of a country: positive for post-transitional countries and negative, but generally non significant, for pre-transitional countries.

These results imply that the negative effect in the pooled sample and the heterogenous effect in pre- and post-transitional countries do not depend on the particular identification strategy, since they hold with the predicted mortality instrument proposed by Acemoglu and Johnson (2007), with OLS, and with the instruments suggested by Lorentzen et al. (2008). Moreover, these results suggest that the opposite findings obtained by Acemoglu and Johnson (2007) and Lorentzen et al. (2008) do not depend on the use of different instruments, but rather on the estimation of a linear specification that is estimated on samples with different composition regarding pre-transitional and post-transitional countries.

Throughout the different estimations, the effects of life expectancy on GDP per capita have consistently opposite signs for pre- and post-transitional countries. For post-transitional countries, the results show a positive effect on GDP per capita, but a negative effect on population growth. Estimating a fully interacted model allows us to perform specification tests on a nested model and makes the results more directly comparable to the results obtained from the pooled and partially interacted specifications. In some cases, the partially interacted model appears to be more appropriate, but most importantly, the results consistently suggest that the effect of life expectancy is heterogeneous across pre-transitional and post-transitional countries. This is illustrated by statistics of Chow-tests of equality of $\pi^{\text {pre }}=\pi^{\text {post }}$ in the two samples that are reported in the bottom of the panel and that represent a direct test of condition (7). In most cases, the effects of life expectancy on income per capita appear to be significantly different in the pre-transitional and post-transitional countries, and in the cases where the null of equal coefficients is not rejected in the fully interacted model, we find a strongly positive effect of life expectancy for post-transitional countries in the semi-interacted model. The results over the longer period 1940-2000, reported in Panels (B) are qualitatively identical to those for 1940-1980 although the coefficient estimates are generally larger. The different effects of life expectancy on per capita GDP in pre-transitional and post-transitional countries are not driven by the length of the observation period. Also in the corresponding estimates for log population presented in Table 3, the equality of the effect of life expectancy, $\pi$ can generally be rejected.

Given the estimation in first differences, the common time trend represents the estimate of the constant of the regression in changes, and essentially captures the average change of the dependent variable over the period 1940-1980. A significant value of the common time trend can be interpreted as the change in log income (or population) that is unrelated to the 
differential changes in life expectancy within each sample. The positive values of the common time trend reported in Table 2 imply a positive average increase in per capita income over the period 1940-1980, which appears to be larger for pre-transitional countries, consistent with a convergence process. The time trend is almost three times larger in pre-transitional countries compared to post-transitional countries over the period 1940-1980. In restricting the time trend in post-transitional countries to be the same as in pre-transitional countries, the partially interacted model underestimates the effect of life expectancy as is indicated by the larger estimates obtained with the fully interacted model.

\subsection{Oaxaca-Blinder decompositions}

To investigate whether the variation in growth rates across pre-transitional and post-transitional countries results from different variation in life expectancy, or from different coefficients at different stages of the demographic transition, one can decompose the predicted difference in GDP growth following Oaxaca (1973) and Blinder (1973). ${ }^{30}$ The difference in predicted log GDP per capita growth between pre-transitional and post-transitional countries over the period 1940-1980, ${\widehat{\Delta \ln y_{i}}}^{\text {post }}-{\widehat{\Delta \ln y_{i}}}^{\text {pre }}$, is 1.09 for the specification in column (3) of Panel (A) of Table 2. This difference can be decomposed into a conditional convergence process, reflected in the relatively higher time trend estimate for pre-transitional (underdeveloped) countries, with an difference in the coefficients of $\widehat{\Delta \mu}^{\text {post }}-\widehat{\Delta \mu}^{\text {pre }}=$ $0.66-3.31=-2.65$. Also, the larger average improvement in life expectancy in these countries of $\overline{\Delta \ln T}^{\text {pre }}-\overline{\Delta \ln T}^{\text {post }}=0.59-0.24=0.35$, evaluated at the coefficient estimate for post-transitional or pre-transitional countries, favors pre-transitional countries over post-transitional countries.

The difference in the coefficient estimates, i.e., the distinct causal effects of life expectancy on income per capita in pre-transitional and post-transitional countries, however, exacerbates the differences in incomes, and even leads to substantially larger predicted growth differences than what is actually observed. Depending on the base category, the corresponding difference in predicted growth is $\overline{\Delta \ln T}^{\text {post }}\left[\hat{\pi}^{\text {post }}-\hat{\pi}^{\text {pre }}\right]=0.59[2.29-(-5.45)]=4.54$ when evaluated at the average change in pre-transitional countries, $\overline{\Delta \ln T}^{\text {pre }}=0.59$, or $\overline{\Delta \ln T}^{\text {post }}\left[\hat{\pi}^{\text {post }}-\hat{\pi}^{\text {pre }}\right]=0.24[2.29-(-5.45)]=1.84$ when evaluated at $\overline{\Delta \ln T}^{\text {post }}=$ $0.24 .^{31}$ These decomposition results are essentially unaffected by the classification criterion one adopts. Hence, in the absence of differential time trends and characteristics that favor pre-

30 In terms of specification (6), the decomposition can be written as

$$
\begin{aligned}
& {\widehat{\Delta \ln y_{i}}}^{\text {post }}-{\widehat{\Delta \ln y_{i}}}^{\text {pre }} \\
& =\left(\overline{\Delta \ln T}^{\text {post }}-\overline{\Delta \ln T}^{\text {pre }}\right) \hat{\pi}^{\text {post }}+\overline{\Delta \ln T}^{\text {pre }}\left(\hat{\pi}^{\text {post }}-\hat{\pi}^{\text {pre }}\right)+\left(\widehat{\Delta \mu}^{\text {post }}-\widehat{\Delta \mu}^{\text {pre }}\right) \\
& =\left(\overline{\Delta \ln T}^{\text {post }}-\overline{\Delta \ln T}^{\text {pre }}\right) \hat{\pi}^{\text {pre }}+\overline{\Delta \ln T}^{\text {post }}\left(\hat{\pi}^{\text {post }}-\hat{\pi}^{\text {pre }}\right)+\left(\widehat{\Delta \mu}^{\text {post }}-\widehat{\Delta \mu}^{\text {pre }}\right),
\end{aligned}
$$

where $\overline{\Delta \ln T}^{j}$ denotes the mean change in life expectancy in sample $j$, which are $\overline{\Delta \ln T}$ pre $=0.59$ and $\overline{\Delta \ln T}^{\text {post }}=0.24$ for the period 1940-1980, and the $\hat{\pi}^{j}$ reflect the respective coefficient estimates as displayed in column (3) of Panel (A) of Table 2. Due to the fact that the predicted mortality instrument does not vary in the second observation period by construction, it is not possible to apply a dynamic decomposition approach, e.g., following Juhn et al. (1993).

31 As shown by Elder et al. (2010), the coefficient estimate of a group indicator in a pooled sample represents a weighted average of the unexplained gaps from the two Oaxaca-Blinder decompositions, providing a summary statistic for the unexplained component of the growth gap. 
transitional countries, the heterogeneity in the causal effects would imply a larger difference in growth rates across the sub-samples than what one observes in the data.

\subsection{The role of sample composition}

As documented above, the opposite findings obtained by Acemoglu and Johnson (2007) and Lorentzen et al. (2008) are not due the application of different instrumentation strategies. In the presence of non-monotonic effects, the application of a linear estimation framework may deliver misleading results since the estimates are very sensitive to the sample composition in terms of pre- and post-transitional countries. The role of the sample composition can be illustrated by giving different weights to the different countries by maintaining the linear estimation framework as Acemoglu and Johnson (2007). Specifically, after ordering the countries according to their initial conditions in terms of initial life expectancy (or crude birth rates in 1940) we estimate the model on the pooled sample after assigning weights to the different observations according to a weighting function. This function gives higher weight to countries with similar initial conditions as a particular reference country, as compared to countries with more dissimilar initial conditions. ${ }^{32}$ This procedure delivers information on the effect of life expectancy using the full sample, but it accounts for the role of the different stages of demographic development by giving different weights to countries in different stages of the demographic transition without relying on any classification criteria or thresholds.

If the hypothesis of different effects of life expectancy at different stages of the demographic transition is false, the procedure should deliver similar results regardless of the country used as center for the weighting. The results, summarized in Fig. 8 for GDP per capita and in Fig. 9 for population, show that this is not the case. ${ }^{33}$ The estimated effect of life expectancy on growth is monotonically increasing the greater the weight given to post-transitional countries. In particular, the effect is positive when a large weight is given to countries with large initial life expectancy (or low crude birth rates) and negative when the large weight is given to the countries at the other extreme. This is consistent with the hypothesis that the effect of life expectancy on income per capita differs depending on the initial level of life expectancy and crude birth rates. The opposite picture emerges for population growth rates which are negative for post-transitional and positive for pre-transitional countries. Consistent with the typical patterns summarized in Fig. 1, the effect of life expectancy on population growth is hump-shaped and largest when giving weight to intermediate countries that are those most likely to enter the demographic transition shortly after 1940. When ordering the countries in terms of initial income the results are qualitatively similar but the estimates are more similar to the un-weighted results estimated by Acemoglu and Johnson (2007). This further suggests

\footnotetext{
32 In the limit, giving zero weight to a country is equivalent to excluding it from the sample. In the estimation, we use a log-logistic weighting function of the form $1-a x^{b} /\left(1+a x^{b}\right)$, where $x$ measures the distance in ranks with respect to the reference country's initial conditions, and $a, b>0$ are smoothing parameters. This weighting function is illustrated in Fig. 12 in the Online Appendix. This specification of the weight function has the advantage of allowing for comparable weights to countries with relatively similar initial conditions, in the example within a range of about 20 countries, but assigning rapidly decreasing weights to countries outside this range. The procedure delivers 47 estimates from estimating the model for each single country as center for the weighting function. Notice that the quantitative results depend on the choice and parametrization of the weighing function. The results are therefore meant as an illustration of the role of sample composition.

33 The figures plot the coefficient estimates of $\pi$ and the corresponding $95 \%$ confidence intervals against the position that the respective country at the center of the weighting function takes in the ranking of initial conditions. Initial conditions are ordered by demographic development (increasing initial life expectancy and decreasing in initial crude birth rates). The larger variation in the estimates at the boundaries of the support is due to the symmetric weighting, which implies a lower effective sample size at the boundaries.
} 


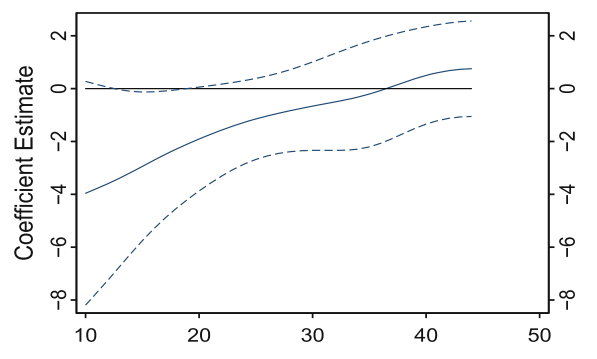

Center of Weighting (Rank of Initial Life Expectancy)

(a)

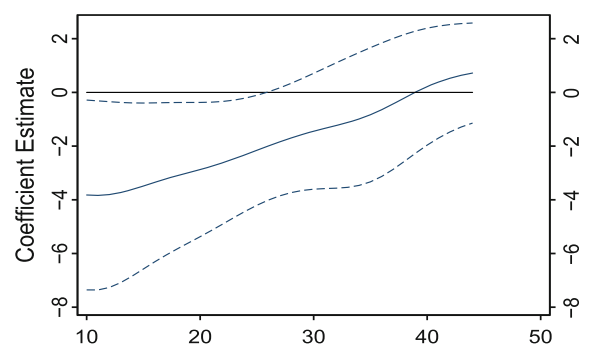

Center of Weighting (Rank of Initial Life Expectancy)

(c)

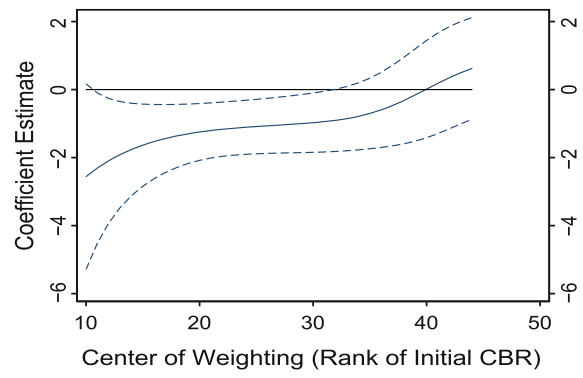

(b)

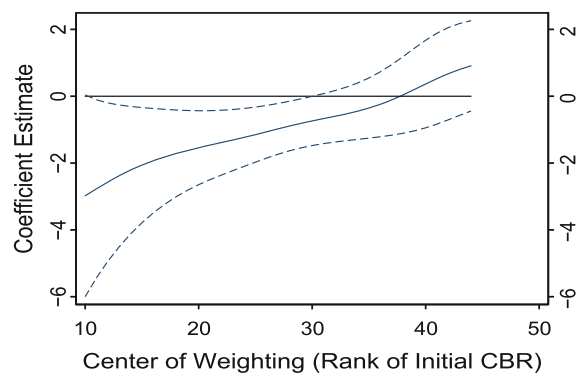

(d)

Fig. 8 Weighted estimates: causal effect of life expectancy on income per capita. a Effect for 1940-1980. Countries ordered by LEB 1940. b Effect for 1940-1980. Countries ordered by CBR 1940. c Effect for 19402000. Countries ordered by LEB 1940. d Effect for 1940-2000. Countries ordered by CBR 1940. Results from 2SLS regression using the specification by Acemoglu and Johnson (2007) on the full sample. The regressions are weighted using the log logistic function depicted in Figure 12 (Online Appendix). Countries are ordered according to ascending life expectancy at birth (LEB) and descending in crude birth rate (CBR) in 1940, and iteratively used as center for the weighting function as discussed in the text

that the more relevant ordering refers to demographic conditions and that what matters is the different stages of the demographic transition rather than the level of development per se. By demonstrating the consequences of sample composition for the estimates obtained with a linear specification, these results also illustrate how accounting for non-monotonic effects can reconcile the different results on the causal role of life expectancy for growth that have been found in the literature.

\subsection{Life expectancy and the demographic transition}

From Figs. 3 and 4 it is evident that some pre-transitional countries undergo the demographic transition during the observation period. To investigate the hypothesis that increases in life expectancy might be causal for reducing fertility and triggering the demographic and economic transition, we estimate linear probability models of whether or not a country has undergone the demographic transition in the period after 1940. The dependent variable takes value 1 if a country passes from being pre-transitional in 1940 to being post-transitional in 1980 (or 2000) and it takes value 0 otherwise. We use the same identification strategy based on the predicted mortality instrument. The validity of the exclusion restriction that the instrument (the predicted drop in mortality due to the epidemiological revolution) is exogenous to 


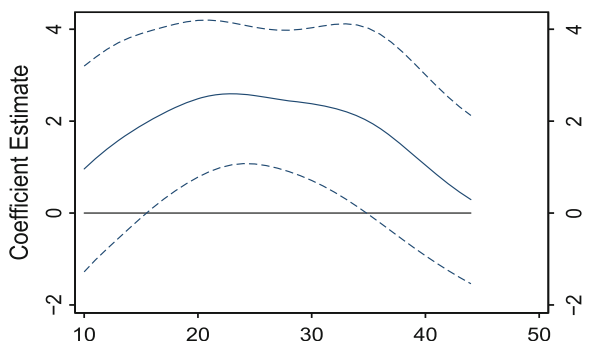

Center of Weighting (Rank of Initial Life Expectancy)

(a)

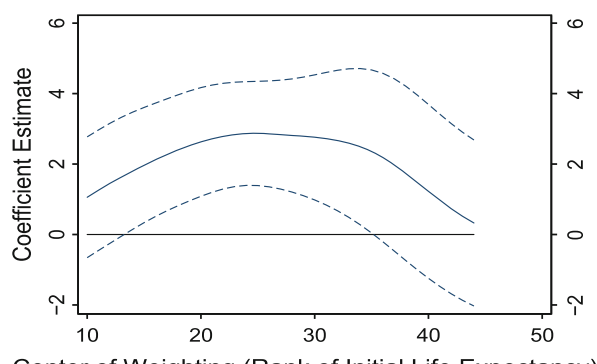

Center of Weighting (Rank of Initial Life Expectancy)

(c)

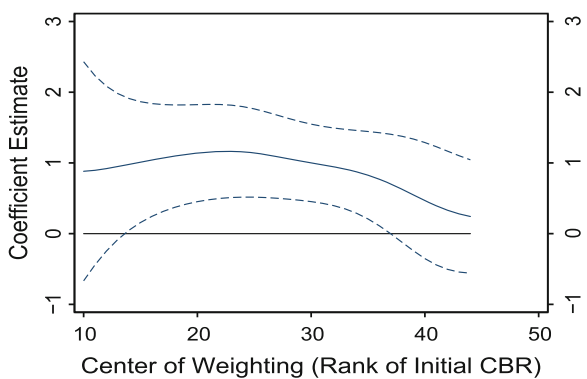

(b)

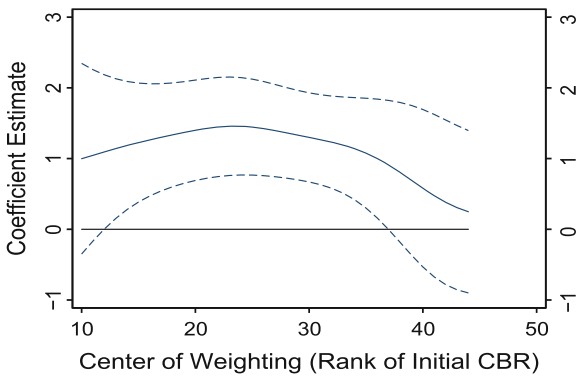

(d)

Fig. 9 Weighted estimates: causal effect of life expectancy on population. a Effect for 1940-1980. Countries ordered by LEB 1940. b Effect for 1940-1980. Countries ordered by CBR 1940. c Effect for 1940-2000. Countries ordered by LEB 1940. d Effect for 1940-2000. Countries ordered by CBR 1940. Results from 2SLS regressions. The weighting function is discussed in the text and reported in Figure 12. Countries are ordered according to ascending life expectancy at birth (LEB) and descending in crude birth rate (CBR) in 1940, and iteratively used as center for the weighting function as discussed in the text.

the outcome of interest (the probability to undergo the demographic transition) and affects the outcome through no other channel than through its effect on life expectancy, is essentially based on the same assumptions as in the benchmark analysis.

The results are presented in Table 4. Panel (A) contains the results for undergoing the transition during the observation period 1940-1980, while panel (B) shows results for the period 1940-2000. Column (1) shows that an increase in life expectancy significantly increases the probability of a country that has life expectancy at birth below 50 years in 1940 to undergo a transition to life expectancy above 50 by 1980 (panel (A)) or by 2000 (panel (B)). The results of columns (2) and (3) document that larger life expectancy also increases the probability of observing a demographic transition when applying the criterion of a sustained fertility drop and crude birth rates below 30/1000. With regard to a transition in crude birth rates, the effect is positive and insignificant over the shorter horizon, but positive and significant over the longer horizon (see Panel (B)), which might have to do with the lower number of transitions (8) according to this criterion over the short horizon. For robustness and completeness, columns (4)-(6) report the respective estimates when using the instrumentation strategy by Lorentzen et al. (2008). The results are qualitatively identical and even stronger. Overall, the results suggest that an increase in life expectancy appears to significantly increase the probability that a country undergoes the demographic transition. 


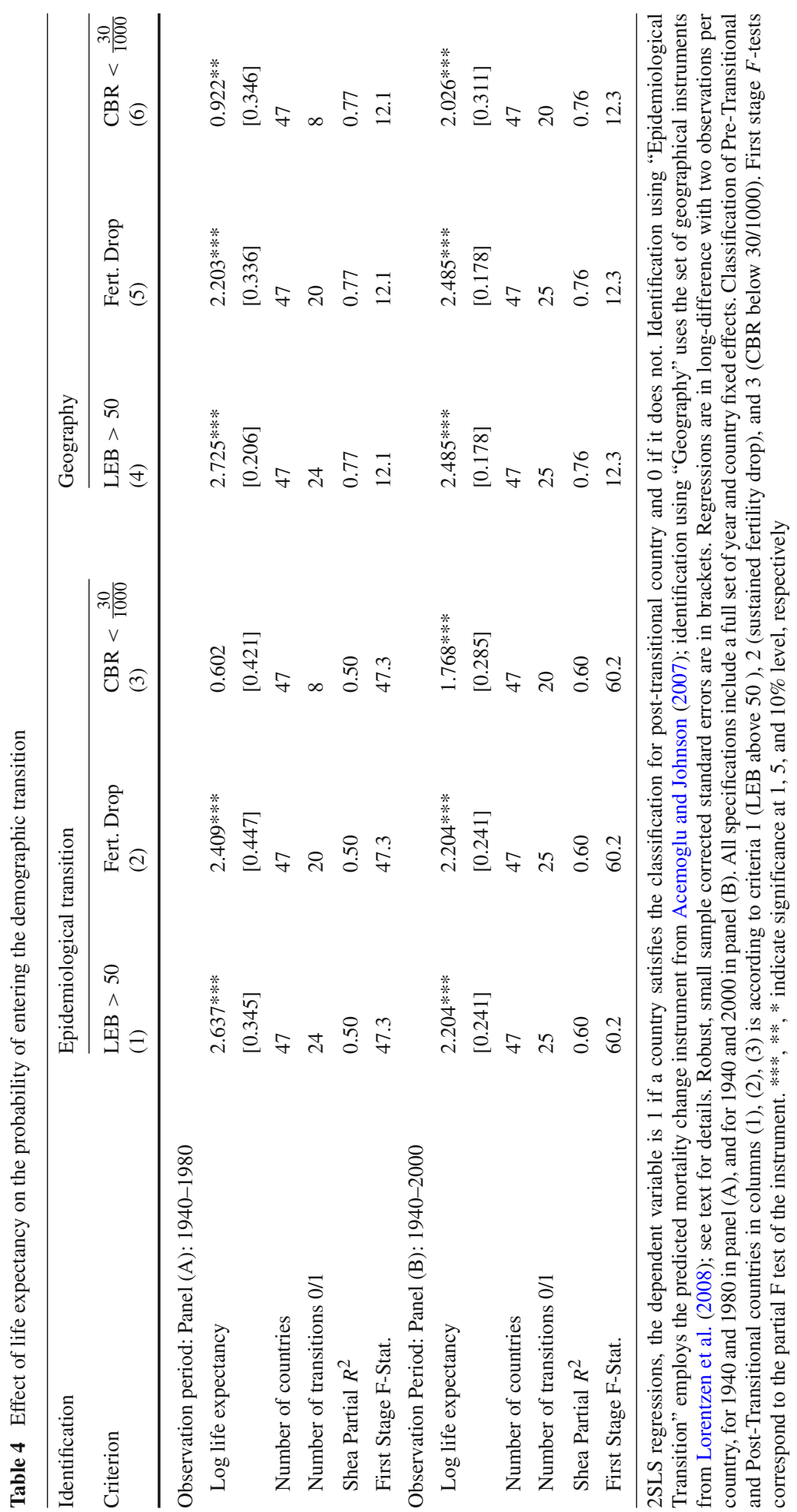




\subsection{Robustness}

This section discusses the results of several robustness checks, including the use of alternative classification criteria, the instrumentation of the initial demographic status and the explicit consideration of initial conditions. The details are reported in the additional material in the Online Appendix.

\subsection{Robustness to alternative classification criteria}

The results are qualitatively identical when using alternative classification criteria. The main difference is that the negative effect on income grow in pre-transitional countries is sometimes statistically significant (see Table 9 in the Online Appendix). When countries are classified in terms of their initial income levels the results are qualitatively similar. As shown by Acemoglu and Johnson (2007), the effect of life expectancy on income per capita is significantly negative for the poor and middle income countries. They are, however, positive for the high income countries (see Table 10 in the Online Appendix). This should be expected in view of the close link between economic and demographic development that underlies most of the unified growth literature. It should be noted, however, that it is well documented in the literature, that the demographic transition may take place for quite different levels of income and in very different socio-economic environments, see Kirk (1996). For example, in 1940 several European countries are classified as non-rich although they were clearly already post-transitional (the sub-sample of non-rich countries isolated by Acemoglu and Johnson 2007, includes 36 countries, eleven of which where already post-transitional in terms of the demographic criteria). The findings are consistent with the role of demographic dynamics that one would expect from the literature cited above. While the findings do not provide a proof that initial demographic conditions are more relevant than initial income in explaining the heterogenous effects documented above, it is not straightforward to think of a consistent explanation for why the effect of life expectancy on income growth should be opposite depending on the level of initial income per se, beyond (and differently from) the role of the demographic variables discussed above. The different effects of life expectancy on population growth are, in turn, clearly related to population dynamics. Together with the results of the weighted estimations presented in Sect. 4, the findings overall suggest that the explicit consideration of the role of the demographic transition, and the associated population dynamics, are important factors for the interpretation of the findings beyond the role of initial income.

\subsection{Instrumenting the status of the demographic transition}

The initial demographic status, whether a country is pre-transitional or post-transitional in 1940, is pre-determined with regard to the epidemiological revolution and the growth in population or income per capita after 1940. Nevertheless, in order to investigate whether the results are affected by potential endogeneity of the demographic status, we also estimated models in which the status of pre-transitional or post-transitional is instrumented by using the set of geographical instruments proposed by Lorentzen et al. (2008). These instruments exploit cross-country variation that strongly correlated with initial life expectancy in 1940. The identification assumptions are essentially the same ones made by Lorentzen et al. (2008), with the only difference that the instrumented variable is binary 
rather than continuous. The results are presented in Table $5 .{ }^{34}$ The findings provide the same qualitative picture: improvements in life expectancy have a positive effect on income per capita growth in post-transitional countries, but no significant effect in pre-transitional countries. This is complemented by a significant negative effect on population growth in posttransitional countries, but a positive effect on population growth in pre-transitional countries. The lower parts of the different panels report first stage statistics and suggest that the instruments work well for both change in life expectancy and demographic status. The estimates are similar to those obtained when treating the transition status as exogenous, and they are robust to the use of different classification criteria.

\subsection{Initial conditions}

We also investigated the robustness of the results with respect to controlling for initial conditions. ${ }^{35}$ The results suggest that the finding of differential effect in pre- and post-transitional countries does not depend on the omission of initial conditions. They support the hypothesis of (stronger) positive effects of improvements in life expectancy on income per capita for post transitional countries, while the opposite holds for population. Notice that this specification does not directly relate to the testable implications derived in Sect. 2 in view of the available theory and evidence. Also, the specification with initial life expectancy cannot be derived by taking differences of the specification in levels as is done in Sect. 3 and is therefore not directly comparable to the specification in levels with country fixed effects as in Acemoglu and Johnson (2007) and the analysis performed above. Finally, in the present context of a long panel with only two observations per country, the change in life expectancy and the initial conditions contain very similar information and are highly correlated by construction. This makes it difficult to discriminate the effects of changes of life expectancy and of initial levels. ${ }^{36}$

\section{Concluding remarks}

This paper has investigated the causal effect of life expectancy on income per capita and tested the hypothesis that the effect may be non monotonic: possibly negative before the demographic transition but unambiguously positive after its onset. The hypothesis emerges from the economic and demographic literature that views long-run economic development as closely related to the non-monotonic population dynamics associated with the demographic transition. The recent unified growth literature provides several arguments suggesting that increasing life expectancy may lead to negative effects on growth in incomes per capita only before the demographic transition, i.e., when life expectancy increases population growth.

\footnotetext{
34 Tables 11 and 12 in the Online Appendix present the respective results for the alternative classification criteria.

35 Controlling for initial life expectancy to account for convergence and level effects has been proposed by Bloom et al. (2009) and Aghion et al. (2011). As instrument for initial life expectancy in 1940, we use again the instruments suggested by Lorentzen et al. (2008). The estimation results for income per capita and population, respectively, are shown in Tables 13 and 14 in the Online Appendix.

36 The respective estimation results of specification (1) of Table 13 (Online Appendix) deliver coefficients of 3.72 and 3.06 for the change and initial level of life expectancy, respectively, which are not statistically different from each other. Also, the first stage regressions reveal that the instruments load fairly similarly on changes and initial levels, with the geographical instruments by Lorentzen et al. (2008) exhibiting slightly larger effects on changes than the predicted mortality instrument by Acemoglu and Johnson (2007). The standard errors increase fivefold compared to the baseline specification in Table 2.
} 
Table 5 Causal effect of life expectancy: instrumenting the demographic status as of 1940

\begin{tabular}{|c|c|c|c|c|c|c|}
\hline \multirow[t]{2}{*}{ Period } & \multicolumn{3}{|l|}{$1940-1980$} & \multicolumn{3}{|l|}{$1940-2000$} \\
\hline & (1) & (2) & (3) & (4) & (5) & (6) \\
\hline \multicolumn{7}{|c|}{ Panel (A): log GDP per Capita } \\
\hline \multirow[t]{2}{*}{ Ln Life Exp. } & 0.198 & $1.273 * *$ & -0.418 & -0.273 & -0.224 & -1.901 \\
\hline & {$[0.326]$} & {$[0.618]$} & {$[0.726]$} & {$[0.483]$} & {$[1.122]$} & [1.306] \\
\hline \multirow[t]{2}{*}{ Ln Life Exp.*Post } & $2.679 * * *$ & & $2.682 * * *$ & $1.942 * *$ & & $4.143 * * *$ \\
\hline & {$[0.403]$} & & {$[0.853]$} & {$[0.802]$} & & {$[1.459]$} \\
\hline \multirow[t]{2}{*}{ Time Trend } & $0.578 * * *$ & 0.081 & $0.895 * *$ & $1.124 * * *$ & 1.134 & $2.124 * *$ \\
\hline & {$[0.144]$} & {$[0.305]$} & {$[0.372]$} & {$[0.313]$} & [0.709] & {$[0.834]$} \\
\hline \multirow[t]{2}{*}{ Time Trend*Post } & & $0.781 * * *$ & -0.224 & & 0.397 & -1.187 \\
\hline & & {$[0.200]$} & {$[0.383]$} & & {$[0.467]$} & {$[0.848]$} \\
\hline Shea Partial $R^{2}$ & 0.58 & 0.60 & 0.77 & 0.60 & 0.59 & 0.79 \\
\hline Shea Partial $R^{2}$ Post & & 0.70 & 0.82 & & 0.66 & 0.84 \\
\hline Shea Partial $R^{2}$ Interact & 0.62 & & 0.87 & 0.62 & & 0.87 \\
\hline Hansen $J$-test $p$-value & 0.26 & 0.20 & 0.25 & 0.20 & 0.17 & 0.36 \\
\hline Number of countries & 47 & 47 & 47 & 47 & 47 & 47 \\
\hline \multicolumn{7}{|l|}{ Panel (B): $\log$ Population } \\
\hline \multirow[t]{2}{*}{ Ln Life Exp. } & $1.079 * * *$ & 0.382 & 0.384 & $1.088 * * *$ & 0.228 & 0.215 \\
\hline & {$[0.253]$} & {$[0.384]$} & {$[0.414]$} & {$[0.293]$} & {$[0.491]$} & {$[0.517]$} \\
\hline \multirow[t]{2}{*}{ Ln Life Exp.*Post } & $-1.662 * * *$ & & -0.908 & $-2.195^{* * *}$ & & -1.017 \\
\hline & {$[0.293]$} & & {$[0.586]$} & {$[0.361]$} & & {$[0.729]$} \\
\hline \multirow[t]{2}{*}{ Time Trend } & $0.482 * * *$ & $0.828 * * *$ & $0.827 * * *$ & $0.755 * * *$ & $1.277 * * *$ & $1.285 * * *$ \\
\hline & [0.117] & {$[0.190]$} & {$[0.206]$} & {$[0.172]$} & {$[0.300]$} & {$[0.312]$} \\
\hline \multirow[t]{2}{*}{ Time Trend*Post } & & $-0.542 * * *$ & -0.37 & & $-0.860 * * *$ & $-0.624^{*}$ \\
\hline & & {$[0.121]$} & {$[0.229]$} & & {$[0.188]$} & {$[0.347]$} \\
\hline Shea Partial $R^{2}$ & 0.58 & 0.60 & 0.77 & 0.60 & 0.59 & 0.79 \\
\hline Shea Partial $R^{2}$ Post & & 0.70 & 0.82 & & 0.66 & 0.84 \\
\hline Shea Partial $R^{2}$ Interact & 0.62 & & 0.87 & 0.62 & & 0.87 \\
\hline Hansen $J$-test $p$-value & 0.26 & 0.20 & 0.25 & 0.20 & 0.17 & 0.36 \\
\hline Number of countries & 47 & 47 & 47 & 47 & 47 & 47 \\
\hline
\end{tabular}

Results from 2SLS regressions, the dependent variable is log GDP per capita, $y$ in Panel (A) and log population, ln N, in Panel (B); the instrument for change in log life expectancy is predicted mortality change taken from Acemoglu and Johnson (2007), the instrument for pre-/post-transitional is the set of geographic instruments used by Lorentzen et al. (2008), see text for details. Robust, small sample corrected standard errors are in brackets. All regressions are in long-difference specifications with two observations per country, for 1940 and 1980 in panel (A), and for 1940 and 2000 in panel (B), respectively. All specifications include a full set of year and country fixed effects. The estimates correspond to the specifications in Table 2. Classification of Pre-Transitional in 1940 and Post-Transitional in 1940 according to the analysis in Sect. 3. First stage $F$-tests correspond to the partial $\mathrm{F}$ test of the instrument. ***, **, * indicate significance at 1,5 , and $10 \%$ level, respectively

The positive effect of life expectancy may also be reinforced through different channels that are related to reduced fertility rates. The demographic transition, during which the positive relationship between life expectancy and population growth becomes negative, therefore appears to be an important turning point for many direct and indirect channels through which life expectancy may positively affect income per capita. 
The analysis performed in this paper considers the data and the instrumentation proposed by Acemoglu and Johnson (2007) as benchmark, but relaxes the constraint of estimating causal effects under the restriction of a linear empirical specification. Several empirical strategies are applied to test the hypothesis of a non-monotonic causal effect of life expectancy on income growth. This is done using interacted models that allow for a heterogenous effect of life expectancy in countries pre and post demographic transition, using information on the demographic status as of 1940. The results show that increases in life expectancy accelerate income per capita in countries that had already experienced the onset of the transition by 1940. The effect is opposite in pre-transitional countries but sometimes statistically insignificant, depending on the actual specification. In line with the theoretical predictions, these patterns are complemented by statistically significant opposite effects on population growth.

The results are similar when applying OLS or alternative identification strategies proposed in the literature. By documenting that the findings are qualitatively identical when using the alternative instruments proposed by Lorentzen et al. (2008), the results help reconcile the seemingly contradictory empirical findings in the existing literature. The analysis documents that the mixed results obtained in the literature are not due to the use of different instrumentation strategies. In the presence of non-monotonic effects, the estimates of the causal effect of life expectancy on income growth obtained with a linear estimation framework may be misleading since they crucially depend on the sample composition in terms of pre-transitional and post-transitional countries. The key role of sample composition is documented by weighted estimations on the full sample in a linear framework. The effect of life expectancy on income growth is more positive the larger the weight given to countries that have larger initial life expectancy or lower crude birth rates in 1940. These are the countries which are more likely to be post-transitional. The results document a clear hump shape effect of life expectancy on population growth which is to be expected from the demographic literature. The analysis also provides evidence that life expectancy causally increases the probability of observing the fertility transition. The results are robust to a set of additional checks, including different classification criteria, instrumenting the demographic status of countries as of 1940, and controlling for initial conditions.

The results therefore qualify the conclusions of the previous literature on the causal role of life expectancy on income growth and suggest that life expectancy may have direct effects on economic growth, although they appear to be non-monotonic and depend, in particular, on the level of demographic development. Improvements in life expectancy may also have indirect effects on income growth by increasing the probability of observing the onset of the demographic transition. The findings have relevant policy implications given that most countries in the world have undergone, or progressed towards, the demographic transition. It is important to notice, however, that the analysis also documents that before the onset of the transition life expectancy leads to increases in population growth. This suggests that policies targeted at reducing mortality should be complemented by interventions aiming at reducing fertility to limit the negative effects of population growth during the process of development.

Acknowledgements We thank Josh Angrist, Sascha Becker, Raouf Boucekkine, David Canning, David de la Croix, Carl-Johan Dalgaard, Margherita Fort, David Jaeger, Aart Kraay, Adriana Lleras-Muney, Fabrice Murtin, Davide Raggi, Rudi Stracke, Holger Strulik, Romain Wacziarg and seminar participants at Berne, Bologna, Copenhagen, Engelberg Ski \& Labor Seminar, Hannover, Lucca IMT, Milan Cattolica, St. Gallen, UCLA Anderson, UCLouvain and Health and Macroeconomics Workshop in Madrid for helpful suggestions. Excellent research assistance by Therese Faessler is gratefully acknowledged. 


\section{References}

Acemoglu, D., \& Johnson, S. (2007). Disease and development: The effect of life expectancy on economic growth. Journal of Political Economy, 115(6), 925-985.

Aghion, P., Howitt, P., \& Murtin, F. (2011). The relationship between health and growth: When Lucas meets Nelson-Phelps. Review of Economics and Institutions, 2(1), 1-24.

Ashraf, Q. H., Lester, A., \& Weil, D. N. (2008). When does improving health raise GDP? In D. Acemoglu, K. Rogoff, \& M. Woodford (Eds.), NBER macroeconomics annual (Vol. 23, pp. 157f́b-204). Chicago: University of Chicago Press.

Bar, M., \& Leukhina, O. (2010). Demographic transition and industrial revolution: A macroeconomic investigation. Review of Economic Dynamics, 13(2), 424-451.

Bar, M., \& Leukhina, O. (2011). The role of adult mortality in the transmission of knowledge. Journal of Economic Growth, 15(4), 291-321.

Becker, G.S., Philipson, T.J., \& Soares, R.R. (2005). The quantity and quality of life and the evolution of world inequality. American Economic Review, 95(1), 277-291.

Blackburn, K., \& Cipriani, G.P. (2002). A model of longevity, fertility and growth. Journal of Economic Dynamics and Control, 26, 187-204.

Bleakley, H., \& Lange, F. (2009). Chronic disease burden and the interaction of education, fertility, and growth. Review of Economics and Statistics, 91(1), 52-65.

Blinder, A. S. (1973). Wage discrimination: Reduced form and structural variables. Journal of Human Resources, 8, 436-455.

Bloom, D. E., Canning, D., \& Fink, G. (2009). Disease and development revisited NBER Working Paper No. 15137

Bloom, D. E., Canning, D., Fink, G., \& Finlay, J. E. (2009). Fertility, female labor force participation, and the demographic dividend. Journal of Economic Growth, 14(1), 71-101.

Bloom, D. E., Canning, D., \& Sevilla, J. (2003). The demographic dividend. Santa Monica: RAND.

Bloom, D. E., \& Sachs, J. D. (1998). Geography, demography, and economic growth in Africa. Brookings Papers on Economic Activity, 2, 207-273.

Boldrin, M., \& Jones, L. E. (2002). Mortality, fertility, and saving in a Malthusian economy. Review of Economic Dynamics, 5(4), 775-814.

Boucekkine, R., de la Croix, D., \& Licandro, O. (2002). Vintage human capital, demographic trends, and endogenous growth. Journal of Economic Theory, 104(2), 340-375.

Boucekkine, R., de la Croix, D., \& Licandro, O. (2003). Early mortality declines at the dawn of modern growth. Scandinavian Journal of Economics, 105, 401-418.

Carr-Saunders, A. (1936). World population: Past growth and present trends. Oxford: Claredon University Press.

Cervellati, M., \& Sunde, U. (2005). Human capital, life expectancy, and the process of development. American Economic Review, 95(5), 1653-1672.

Cervellati, M., Sunde, U. (2007). Human capital, mortality and fertility: A unified theory of the economic and demographic transition. IZA Discussion Paper No. 2905.

Chesnais, J.-C. (1992). The demographic transition: Stages, patterns and economic implications, a longitudinal study of sixty-seven countries covering the period 1720-1984. Oxford: Clarendon Press.

de la Croix, D., \& Licandro, O. (1999). Life expectancy and endogenous growth. Economics Letters, 65, 255263.

de la Croix, D., \& Licandro, O. (2007). The father of child is father of man: Implications for the demographic transition. EUI Florence: Mimeo.

Elder, Todd E., J. H., G., \& Haider, S. J. (2010). Unexplained gaps and oaxaca-blinder decompositions. Labour Economics, 17(1), 284-290.

Falcão, B. L., \& Soares, R. R. (2008). The demographic transition and the sexual division of labor. Journal of Political Economy, 116(6), 1058-1104.

Gallup, J. L., Sachs, J. D., \& Mellinger, A. D. (1999). Geography and economic development. International Regional Science Review, 22(2), 179-232.

Galor, O. (2005). From stagnation to growth: Unified growth theory. In P. Aghion \& S. Durlauf (Eds.), Handbook of economic growth (Chap. 4). Amsterdam: Elsevier.

Galor, O. (2010). Comparative economic development: Insights from unified growth theory. International Economic Review, 51(1), 1-44.

Galor, O., \& Moav, O. (2002). Natural selection and the origin of economic growth. Quarterly Journal of Economics, 117(4), 1133-1192.

Galor, O., \& Weil, D. N. (1996). The gender gap, fertility and growth. American Economic Review, 86(3), 374387. 
Galor, O., \& Weil, D. N. (2000). Population, technology, and growth: From malthusian stagnation to the demographic transition and beyond. American Economic Review, 90(4), 806-828.

Jayachandran, S., \& Lleras-Muney, A. (2009). Life expectancy and human capital investments: Evidence from maternal mortality declines. Quarterly Journal Economics, 124(1), 349-398.

Juhn, C., Murphy, K. M., \& Pierce, B. (1993). Wage inequality and the rise in returns to skill. Journal of Political Economy, 101(3), 410-442.

Kalemli-Ozcan, S. (2002). Does mortality decline promote economic growth? Journal of Economic Growth, 7(4), 411-439.

Kalemli-Ozcan, S. (2003). A stochastic model of mortality, fertility, and human capital investment. Journal of Development Economics, 70(1), 103-118.

Kalemli-Ozcan, S., Ryder, H. E., \& Weil, D. N. (2000). Mortality decline, human capital investment, and economic growth. Journal of Development Economics, 62, 1-23.

Kirk, D. (1996). Demographic transition theory. Population Studies, 50, 361-387.

Lagerlöf, N.-P. (2003). From malthus to modern growth: Can epidemics explain the three regimes? International Economic Review, 44(2), 755-777.

Landry, A. (1934). La revolution demographique. Paris: Sirey.

Lee, R. (2003). The demographic transition: Three centuries of fundamental change. Journal of Economic Perspectives, 17(4), 167-190.

Livi-Bacci, M. (1992). A concise history of world population. Oxford: Blackwell.

Lorentzen, P., McMillan, J., \& Wacziarg, R. (2008). Death and development. Journal of Economic Growth, 13(2), 81-124.

Maddison, A. (2003). The eorld economy: Historical statistics. Paris: OECD Development Centre.

Murphy, K. M., \& Topel, R. H. (2006). The value of health and longevity. Journal of Political Economy, 114(5), 871-904.

Notestein, F. (1945). Population: The long view. In T. Schultz (Ed.), Food for the world. Chicago, USA: Chicago University Press.

Oaxaca, R. (1973). Male-female wage differentials in urban labor markets. International Economic Review, 14, 693-709.

Pesaran, M., \& Taylor, L. (1999). Diagnostics for IV regressions. Oxford Bulletin of Economics and Statistics, 61, 255-281.

Preston, S. H., Heuveline, P., \& Guillot, M. (2001). Demography: Measuring and modeling population processes. Oxford: Blackwell.

Reher, D. S. (2004). The demographic transition revisited as a global process. Population, Space and Place, 10(1), 19-41.

Sachs, J. D., Kiszewski, A., D., M. A., Spielmann, A., Malaney, P., \& Ehrlich, S. (2004). A global index of the stability of malaria transmission. American Journal of Tropical Medicine and Hygiene, 70(5), 486-498.

Shastry, G. K., \& Weil, D. (2003). How much of the cross-country variation in income is explained by health?. Journal of the European Economic Association, 1(2-3), 387-396.

Soares, R. (2005). Mortality reductions, educational attainment, and fertility choice. American Economic Review, 95(3), 580-601.

Strulik, H. (2008). Geography, health and the pace of demo-economic development. Journal of Development Economics, 86(1), 61-75.

Thompson, W. S. (1929). Population. American Journal of Sociology, 34, 959-975.

UN. (1983). United nations, manual X: Indirect techniques for demographic estimation. New York: United Nations.

Weil, D. N. (2007). Accounting for the effect of health on economic growth. Quarterly Journal of Economics, 122(3), 1265-1306.

Weil, D., \& Wilde, J. (2009). How relevant is Malthus for economic development today? American Economic Review, 99(2), 255-260.

Wooldridge, J. M. (2002). Econometric analysis of cross-section and panel data. Cambridge, MA: MIT Press. 